\title{
Simulation of Long-Period Ground Motion near a Large Earthquake
}

\author{
by Minoru Takeo and Hiroo Kanamori
}

\begin{abstract}
We estimated the possible range of long-period ground motion for sites located on a soft sedimentary basin in the immediate vicinity of a large earthquake. Since many large cities in the world (e.g., Los Angeles, San Francisco, and Tokyo) where many large structures have been recently constructed are located in this type of environment, a better understanding of long-period ground motion is becoming increasingly important. Our objective is to estimate the possible range of long-period ground motion, rather than ground motion for a specific fault model. We computed ground-motion time series and pseudo-velocity response spectra (PVS) for more than 5,000 models for the 1923 Kanto, Japan, earthquake $\left(M_{W}=7.9\right)$ using 180 slip distributions, eight rupture geometry, and rupture velocities ranging from 1.5 to 3.0 $\mathrm{km} / \mathrm{sec}$. Two seismograms recorded in Tokyo during the 1923 Kanto earthquake are used for comparison. The response spectra computed using seismologically reasonable sets of source parameters for the 1923 Kanto earthquake vary by more than an order of magnitude. At periods of 10 to $13 \mathrm{sec}$, they range from 25 to $170 \mathrm{~cm} / \mathrm{sec}$ in Tokyo. For some combinations of model parameters, the response spectra exhibit peaks in the range of 10 to $13 \mathrm{sec}$. Many of the computed response spectra have peaks at periods longer than $10 \mathrm{sec}$, which is considerably longer than the dominant period $(6$ to $8 \mathrm{sec}$ ) estimated from studies of small earthquakes and microtremor measurements. Thus, the dominant period of the subsurface structure determined locally may not be representative of the dominant period of ground motion from a nearby large earthquake, which is controlled by rupture directivity and source depth. We performed a similar simulation for a hypothetical $M_{W}=7.5$ earthquake located beneath the Los Angeles basin. For a site just above the center of the fault, the ground-motion spectral amplitude at a period of $10 \mathrm{sec}$ can vary from 50 to $350 \mathrm{~cm} /$ sec. This range, though very large, is what is expected for a seismologically plausible range of source parameters.
\end{abstract}

\section{Introduction}

The ever-increasing construction of large-scale structures such as high-rise buildings, oil tanks, suspension bridges, and offshore drilling platforms requires accurate estimation of long-period ( 5 to $20 \mathrm{sec}$ ) ground motions, especially those that could occur in soft sediment-filled basins or landfills where significant amplification could occur. This problem is especially important because many major urban centers in the world are located in such environments (e.g., Los Angeles, San Francisco, and Tokyo). Soft subsurface sediments play a major role in governing the excitation and propagation of such ground motions near the rupture zone of a large earthquake.

With the advent of super computers and numerical techniques, significant advancements have been made recently in estimation of path effects (e.g., Frankel and Vidale, 1992; Frankel, 1993; Olsen et al., 1995). Then, to estimate the actual ground motion, we need to convolve these path effects and site response with the source process. In this article, we address only the question of variability of near-source ground motion due to variations of the source parameters. Our results will eventually have to be convolved with the effects of 3D structures.

Although it would be possible to numerically simulate these motions for a given earthquake model, it is very difficult to verify the simulation results because of the lack of near-source ground-motion data from a very large earthquake $(M=8)$ recorded on such soft structures.

Construction regulations to assure structural integrity against earthquakes are traditionally based on the standard engineering practices that include the use of spectral peaks determined by analysis of strong-motion data from earthquakes, computation of 1D response, or other related methods. In Japan, the design process for high-rise buildings includes the standard regulatory guidelines requiring a 
numerical analysis of its dynamic response to a ground-motion record constructed from some typical observed strongmotion seismograms (e.g., the El Centro record of the 1940 Imperial Valley, California, earthquake and the Taft record of the 1952 Kern County, California, earthquake) and other local earthquakes. To use these records for response studies, the maximum velocity amplitudes are normalized to 50 or $25 \mathrm{~cm} / \mathrm{sec}$. Unfortunately, none of these records measured the motion on soft structures at a location directly above a very large, $M \geqq 7.5$, earthquake. It is clearly desirable to employ more suitable seismograms for such vital design evaluation purposes.

In this regard, three low-gain seismograms recorded at Hongo, Tokyo, during the 1923 Kanto (Tokyo) earthquake in Japan $\left(M_{S}=7.9\right.$ to $\left.8.2, M_{w}=7.9\right)$ are of particular interest. These seismograms were recorded with three different types of seismographs, i.e., Omori strong motion, Imamura strong motion, and Ewing seismographs (Fig. 1). These seismographs were located close to each other on campus of the University of Tokyo. These records are unique because they measured strong ground motions at a site on thick, soft sedimentary layers forming the Kanto Plain, and the site is only $50 \mathrm{~km}$ northeast of the hypocenter.

In view of the engineering importance of near-source long-period ground motion, and of the almost complete lack of such records from a large earthquake, we perform a series of numerical simulations to place bounds on the amplitude and spectrum of near-source ground motion from a very large earthquake expected for sites on a soft sediment-filled basin. The scope of this study is limited to very long-period ( $3 \mathrm{sec}$ or longer) ground motion. Although two specific locations, Tokyo and Los Angeles, are considered, our objective is to address a generic question on the possible range of long-period ground motions. Since this study is an extension of Takeo and Kanamori (1992) (hereafter abbreviated as TK92), there is inevitably some overlap between this article and that of TK92.

\section{Seismograms of the 1923 Kanto Earthquake}

The Imamura seismogram (E-W component) shown in Figure 1a was severely overdriven at about $16 \mathrm{sec}$ after the onset. Apparently, the seismograph stylus hit the damper, which prevented the seismograph from recording the principal part of ground motion for about $30 \mathrm{sec}$. Since the extent of clipping is very excessive, we feel that it is difficult to estimate the actual ground motion from this record. However, Yokota et al. (1989) made an extensive effort to reconstruct the motion of the stylus and estimated the ground motion. Figures $1 \mathrm{~b}$ and $1 \mathrm{c}$ show the reconstructed seismogram and its response spectrum. The spectral amplitudes estimated from this seismogram are more or less in agreement with the common sense view of strong ground motions from very large earthquakes. In contrast, the $\mathrm{N}-\mathrm{E}$ component of the Ewing seismograph recorded the ground motion almost on-scale. However, the recorded ground motion exhibits al- most harmonic motion with a period of about $13 \mathrm{sec}$. Since the natural period of the pendulum is about $6 \mathrm{sec}$, this record with 13-sec harmonic oscillation is often considered very peculiar. Takeo and Kanamori (1992) examined this record in detail and concluded that the resonance of the instrument was probably suppressed by increased solid friction between the stylus and the recording glass plate, and the overall ground motion was correctly recorded. The details are given in TK92. The trace shown in Figure $1 \mathrm{~b}$ is taken from Morioka (1980), and its response spectrum is shown in Figure 1c. The pseudo-velocity response spectrum (PVS) is used throughout this article. The maximum peak-to-peak groundmotion displacement on the NE-SW component is about 90 $\mathrm{cm}$ with a period of $13 \mathrm{sec}$ (Morioka, 1976, 1980; Morioka and Yamada, 1986). The NW-SE component recorded the ground motion with considerably larger amplitudes and was clipped more severely than the NE-SW component. It appears that because of this large amplitude and somewhat unusual character, this record has been discounted by many seismologists and engineers. It often has been thought that the instrument must have malfunctioned and registered the peculiar harmonic motion. However, TK92 demonstrated that the large harmonic motion is not necessarily unrealistic, and a combination of a large earthquake, a soft sedimentfilled structure, and rupture directivity could indeed produce such ground motion.

It is surprising that two seismograms recorded at the same location show significantly different amplitudes and spectra. Although the later part of the Ewing record could have been distorted because of possible mechanical malfunctioning, we believe that there must have been displacements large enough to drive the Ewing seismograph almost to its limit, at least in the beginning. The details of the spectrum computed from the Ewing seismogram may not be very reliable, but the maximum amplitude should be close to what actually occurred. On the other hand, we feel that the amplitude restoration of the Imamura seismogram is subject to large uncertainty because of the excessive clipping, and the spectrum may be close to the lower bound of the groundmotion spectrum. Considering all the difficulties in the interpretation of these seismograms, we do not attempt to model specifically one of these records. Our approach is, instead, to explore the possible range of ground motions expected for sets of seismologically reasonable fault parameters and to evaluate the results in the context of the observed records with the above uncertainties in mind.

\section{Simulation of the 1923 Kanto Earthquake}

Our objective is to determine the range of ground-motion spectral amplitudes for a large number of fault models that are considered realistic for a given area. This approach is desirable because it is not possible to make specific predictions of the magnitude, rupture pattern, and directivity of future earthquakes, yet these factors, especially directivity, have a profound influence on the strength and nature of 
(a)

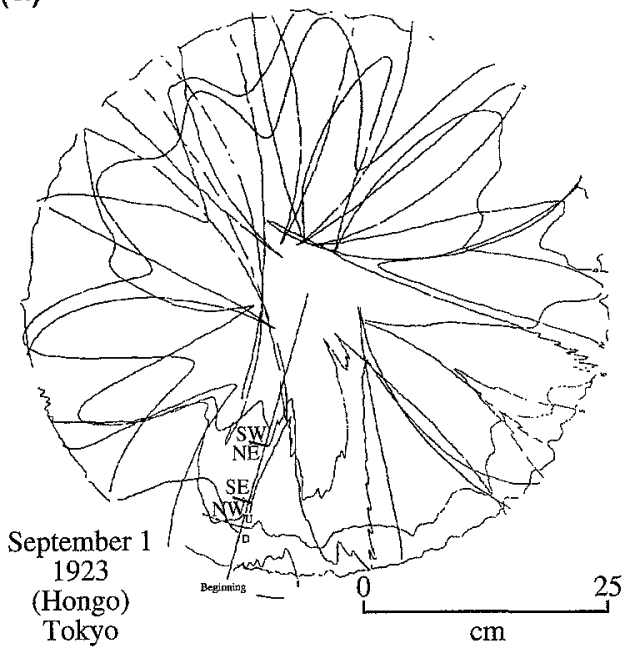

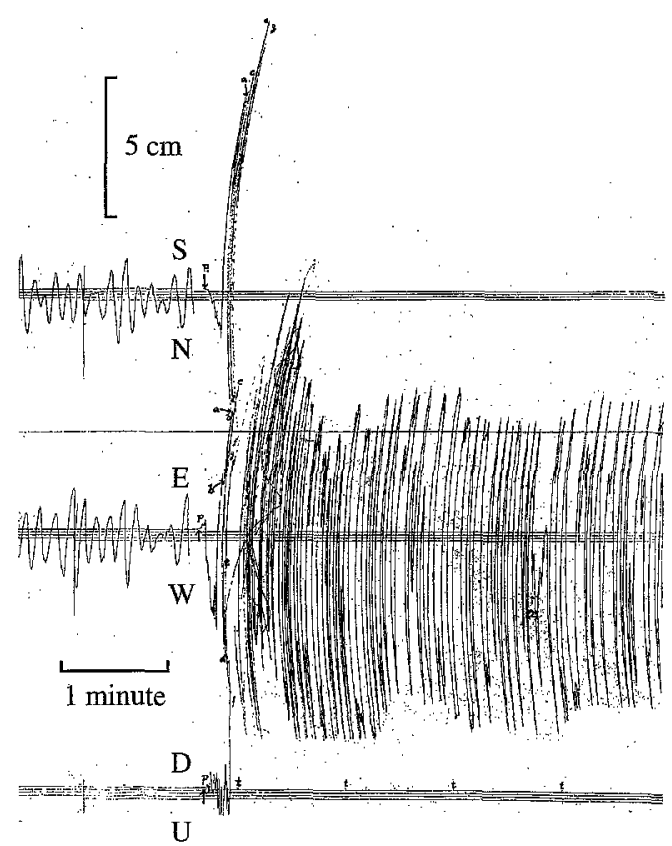

(2) Imamura seismogram

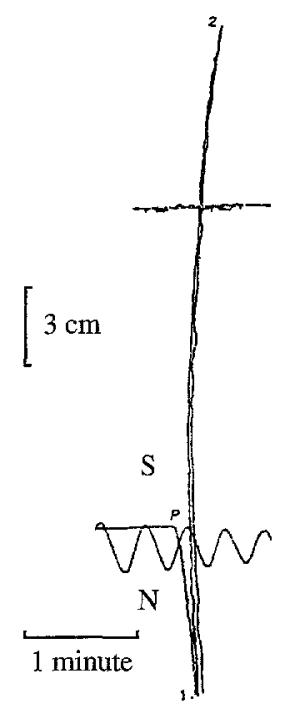

(3) Omori seismogram

(b)
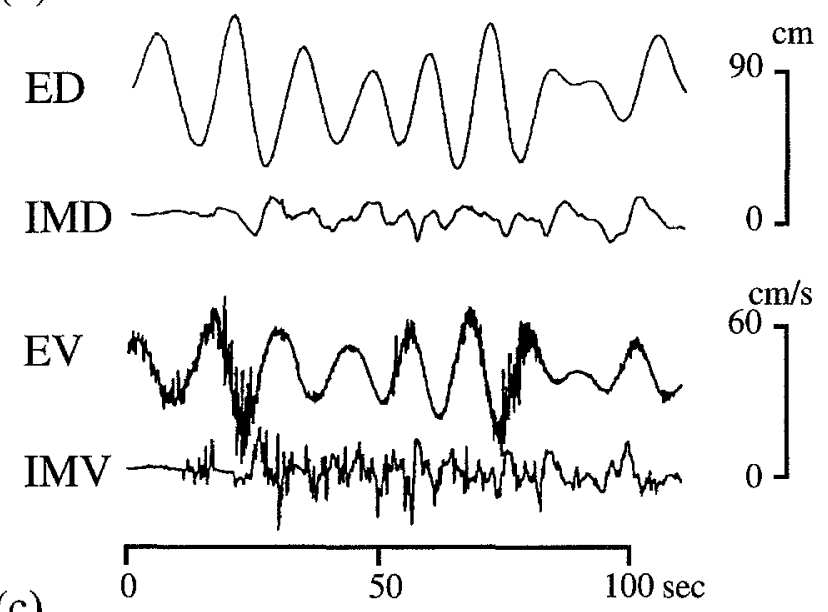

(c)

(1) Ewing seismogram

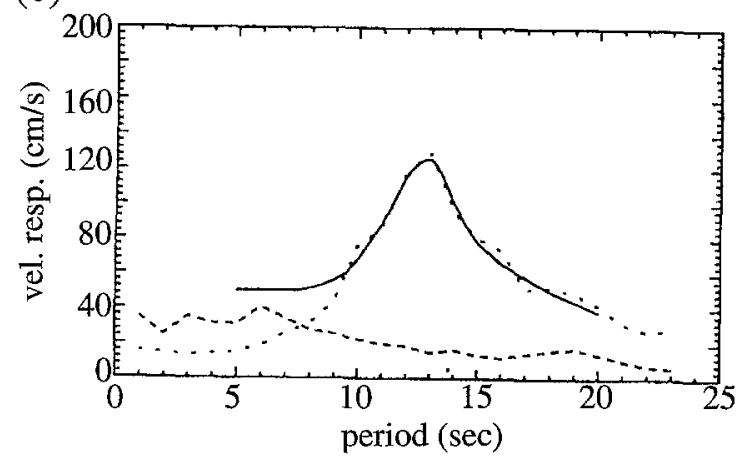

Figure 1. (a) Three low-gain seismograms of the 1923 Kanto earthquake recorded in Hongo, Tokyo, by the Ewing (natural period $T_{0}=6.0 \mathrm{sec}$; damping constant $h=0.045$; magnification $V=1.0)$, the Imamura $\left(T_{0}=10.0 \mathrm{sec}, h\right.$ $=0.17, V=2.0)$, and the Omori $\left(T_{0}=40.0 \mathrm{sec}\right.$, no damper, $V=1.5$ ) seismographs. The NE-SW component of the Ewing seismogram traced by Morioka (1980) is shown just beneath the original trace. The slightly clipped portions were interpolated by Morioka (1980). (b) Groundmotion displacement and velocity estimated from the SWNE component of the Ewing seismogram by Morioka and Yamada (1986) (ED: displacement; EV: velocity), and those from the E-W component of the Imamura seismogram by Yokota et al. (1989) (IMD: displacement; IMV: velocity) after recreating clipped portions. (c) Corresponding velocity response spectra $(h=0.05)$ are also shown. The short-dotted and long-dotted curves show the response spectrum calculated from the Ewing and Imamura seismograms, respectively. The solid curve is a reference spectrum obtained by combining these two spectra (TK92). 
strong ground motion to be experienced near the rupture zone (Wald et al., 1991; Ide et al., 1996; Wald, 1996). It is therefore important to know the possible range of ground motions, in addition to the ground motion for specific cases.

The factors that influence long-period ground motion are slip distribution, directivity, rupture geometry and velocity, and slip velocity or rise time of local dislocation. We will vary these parameters following the general scheme employed in TK92. Since the details are given in TK92, we will briefly explain the method in the following.

\section{Fault Model}

Figure 2 shows the tectonic features, the horizontal projection of the fault plane, and the epicenter of the mainshock, as well as the major aftershocks in the 24-hr period after the mainshock (Kanamori, 1971). Several investigators have determined the fault model (e.g., Kanamori, 1971; Ando, 1971, 1974; Matsu'ura et al., 1980; Ishibashi, 1985; Wald and Somerville, 1995). Kanamori (1971) examined the far-field body and surface waves and the initial portion of the Imamura seismogram (Kanamori, 1974) and obtained the following fault model: dip direction $=\mathrm{N} 20^{\circ}$; dip angle $=34^{\circ}$; fault area $=130 \times 70 \mathrm{~km}^{2}$; right-lateral slip $=2 \mathrm{~m}$; reverse dip slip $=0.65 \mathrm{~m}$; rise time of dislocation $=5 \mathrm{sec}$; and rupture velocity $=3 \mathrm{~km} / \mathrm{sec}$. Matsu'ura et al. (1980) subsequently analyzed the geodetic data and the Imamura seismogram to determine the geometry and size of the fault plane, rupture velocity, and rise time of dislocation. They assumed two fault planes with an east-west alignment for which the total fault area is about half that of Kanamori's. However, as the slip on the west and east faults of the Matsu'ura et al. (1980) model are, respectively, about four and two times larger than the average slip of Kanamori's model, the total seismic moment of their model is about the same as that of Kanamori's.

Wald and Somerville (1995) analyzed geodetic and teleseismic data sets for the 1923 Kanto earthquake to determine both temporal and spatial slip variations. Their model suggests that the most concentrated slip is in the shallow central and western portion of the fault and the maximum slip is approximately $8 \mathrm{~m}$.
In this article, we use Kanamori's fault model as the basic model and investigate the effects of different source parameters on simulated ground motions by perturbing many of them from their reference values.

Although the hypocenter depth is poorly constrained (Kanamori and Miyamura, 1970; Matsu'ura et al., 1980; Hamada, 1987), the epicenter is generally considered to be near the western end of the fault plane (Imamura, 1925; Kunitomi, 1930; Kanamori and Miyamura, 1970), which suggests that the overall rupture propagation initiated from the southwestern end of the fault plane and propagated northeastward.

\section{Fault Geometry and Slip Distribution}

The slip distribution on a fault plane is generally complex. To incorporate this complexity, we used the same method as used in TK92. We divided the $70 \times 130 \mathrm{~km}^{2}$ fault plane (Fig. 2) into $3 \times 3 \mathrm{~km}^{2}$ subfaults. The amount of slip on each subfault is varied so that the overall character of slip distribution is similar to that of the 1968 TokachiOki earthquake $\left(M_{w}=8.2\right)$ determined by Kikuchi and Fukao (1987). The slip on the subfaults is adjusted so that the average is $2.1 \mathrm{~m}$, appropriate for the Kanto earthquake. The Tokachi-Oki earthquake is of comparable size and occurred in a tectonic environment similar to that of the Kanto earthquake. Since the spatial resolution of slip distribution from teleseismic analysis is about $30 \mathrm{~km}$, we assumed that the slip is uniform over a distance of $L=30 \mathrm{~km}$. Since this distance, called the spatial resolution parameter $L$, may also be an important parameter, we will vary it over a range from 12 to $51 \mathrm{~km}$.

To test faults with different slip distribution, we perturbed the model described above randomly and produced a set of fault models with different slip distributions. Thus, this set of fault models, as a whole, exhibits a variety of slip patterns, ranging from a peaked distribution to a more uniform one.

\section{Slip Function of Subfault}

The source-time function of each fault directly influences the overall ground motion. For parameterization purposes, we use the source-time function, $f\left(t ; t_{1}, t_{2}\right)$, shown in (a)

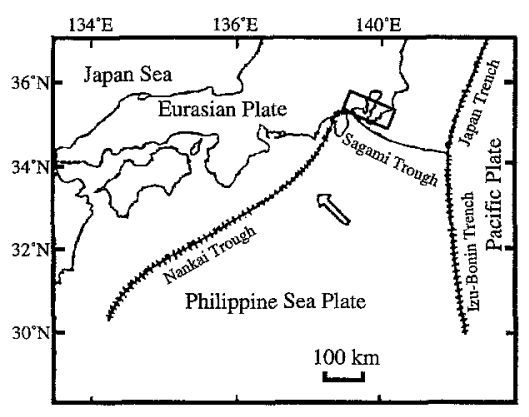

(b)

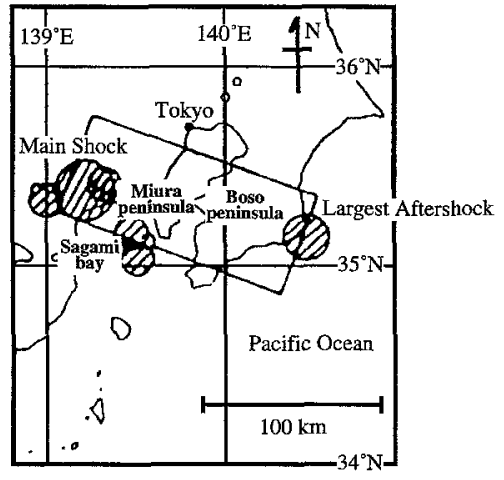

Figure 2. (a) Tectonic structure in southwest Japan. An arrow indicates a slip direction of the Philippine Sea Plate. (b) Horizontal projection of the fault plane of the 1923 Kanto earthquake with the major aftershocks immediately after the mainshock (Kanamori, 1971). 
Figure 3 . The time constants $t_{1}$ and $t_{2}$ correspond to the rupture time and rise time of each subfault, respectively. This source-time function corresponds to the equivalent point-source-time function for a unilateral rupture within each subfault. The $i$ th component of displacement produced by all the subfaults can be expressed as

$$
u_{i}(t)=\sum_{j=1}^{N} m_{j} \int g_{i j}\left(t-t_{s j} ; \tau\right) f\left(\tau ; t_{1}, t_{2}\right) d \tau
$$

where $N$ is the total number of subfaults, $m_{j}$ and $t_{s j}$ are the seismic moment and onset time of the $j$ th subfault, respectively, and $g_{i j}(t ; \tau)$ is the calculated Green's function for the $i$ th component excited by the rupture on the $j$ th subfault at $t=\tau$. The time constant $t_{s j}$ is given by

$$
t_{s j}=r_{j} / v_{r}+t_{m d}
$$

where $v_{r}$ is the rupture velocity, $r_{j}$ the distance from the hypocenter to the nearest point of $j$ th subfault, and $t_{r m d}$ a random value ranging from $-0.1 r_{j} / v_{r}$ to $0.2 r_{j} / v_{r}$. This term is included to add some perturbation to rupture propagation. Since the rupture velocity in the source area is usually slower than the local shear-wave velocity, we use a nonsymmetrical range for $t_{r m d}$ and perform many simulations while randomly varying the slip and rupture patterns. This approach is reasonable considering the large variability of the slip distribution known to have occurred for many large earthquakes.

To assess the effect of rupture propagation and directivity, we considered eight different rupture propagation models (Fig. 4).

\section{Source-time function}

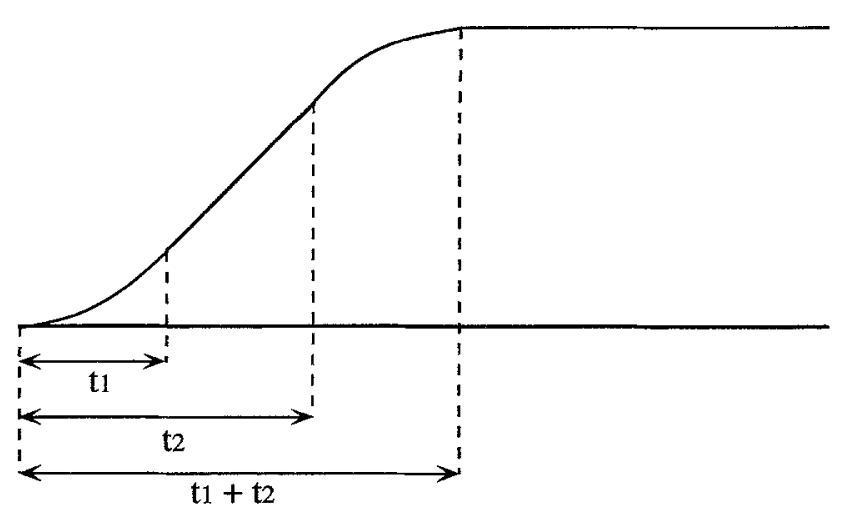

Figure 3. The source-time function used for simulation. $t_{1}$ and $t_{2}$ are the time for the rupture front to propagate through a subfault and the rise time of dislocation, respectively. This function is quadratic in time for the first part (between 0 and $t_{1}$ ) and the last part (between $t_{2}$ and $t_{1}+t_{2}$ ), and linear in time for the middle part (between $t_{1}$ and $t_{2}$ ).

\section{Green's Function}

We computed numerical Green's functions for a layered crustal structure using (1) reflection-transmission matrices (Kennett and Kerry, 1979) and (2) the discrete wavenumber method (Bouchon, 1981) in which an anelastic-layered crustal structure is used (Takeo, 1985). Table 1 summarizes the parameters describing the layered crustal structure for the Kanto Plain derived from the following sources: (1) an explosion study that determined the depth of bedrock beneath Tokyo (Research Group on Underground Structure in Tokyo, 1989), (2) surface-wave group velocity measurements for the paths from Izu peninsula to Tokyo (Kudo, 1980), and (3) the velocity structure in the Sagami Bay (Yamanaka, 1991).

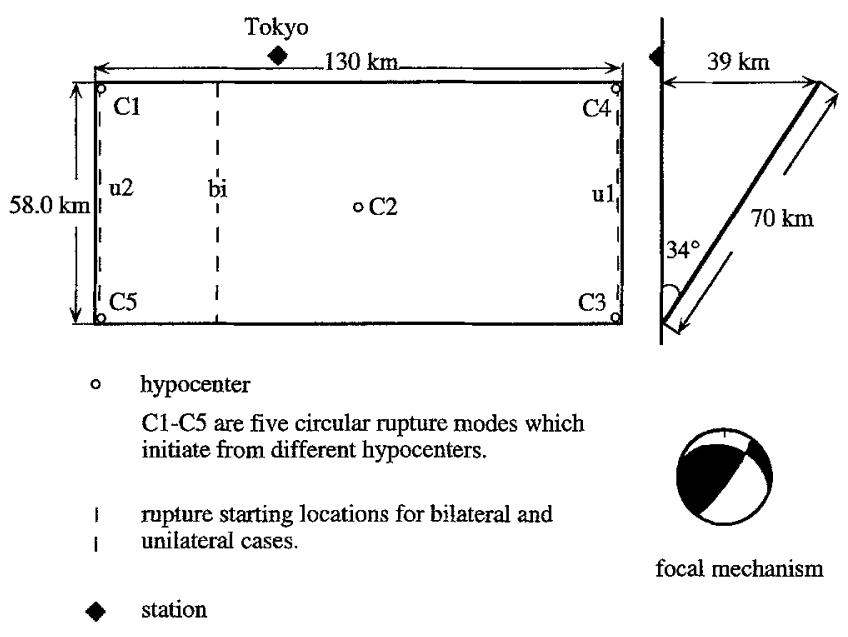

Figure 4. The horizontal projection and the cross section of the fault plane of the 1923 Kanto earthquake. Rupture propagation models used for simulation are also shown. bi: bilateral rupture; $u 1$ and $u 2$ : unilateral rupture; $c 1$ to $c 5$ : circular rupture. The hypocenter depths of the models $c 1$ and $c 4$, of the model $c 2$, and of the models $c 3$ and $c 5$ are 38.3, 19.6, and $0.8 \mathrm{~km}$, respectively. Small, open circles indicate the hypocenters used for the simulations of circular rupture models. The fault parameters of the Kanto earthquake obtained by Kanamori $(1971,1974)$ are dip direction $=\mathrm{N} 20^{\circ} ;$ dip angle $=34^{\circ}$, fault area $=130$ $\times 70 \mathrm{~km}^{2}$; right-lateral slip $=2 \mathrm{~m}$; reverse dip slip $=0.65 \mathrm{~m}$; rise time of dislocation $=5 \mathrm{sec}$; rupture velocity $=3 \mathrm{~km} / \mathrm{sec}$. The focal mechanism used in this article is also shown. The location of Tokyo is indicated by a solid diamond symbol.

Table 1

Velocity Structure Used for Simulation of the Kanto Earthquake

\begin{tabular}{cccccc}
\hline$V_{p}$ & $V_{s}$ & $p$ & \multicolumn{1}{c}{$h$} & $Q_{p}$ & $Q_{s}$ \\
\hline 2.80 & 1.30 & 2.30 & 0.00 & 200 & 100 \\
5.60 & 2.90 & 2.50 & 2.70 & 400 & 200 \\
6.00 & 3.40 & 2.60 & 6.10 & 500 & 230 \\
6.80 & 4.00 & 3.00 & 19.00 & 600 & 270 \\
6.80 & 4.00 & 3.00 & 50.00 & 600 & 270 \\
\hline
\end{tabular}



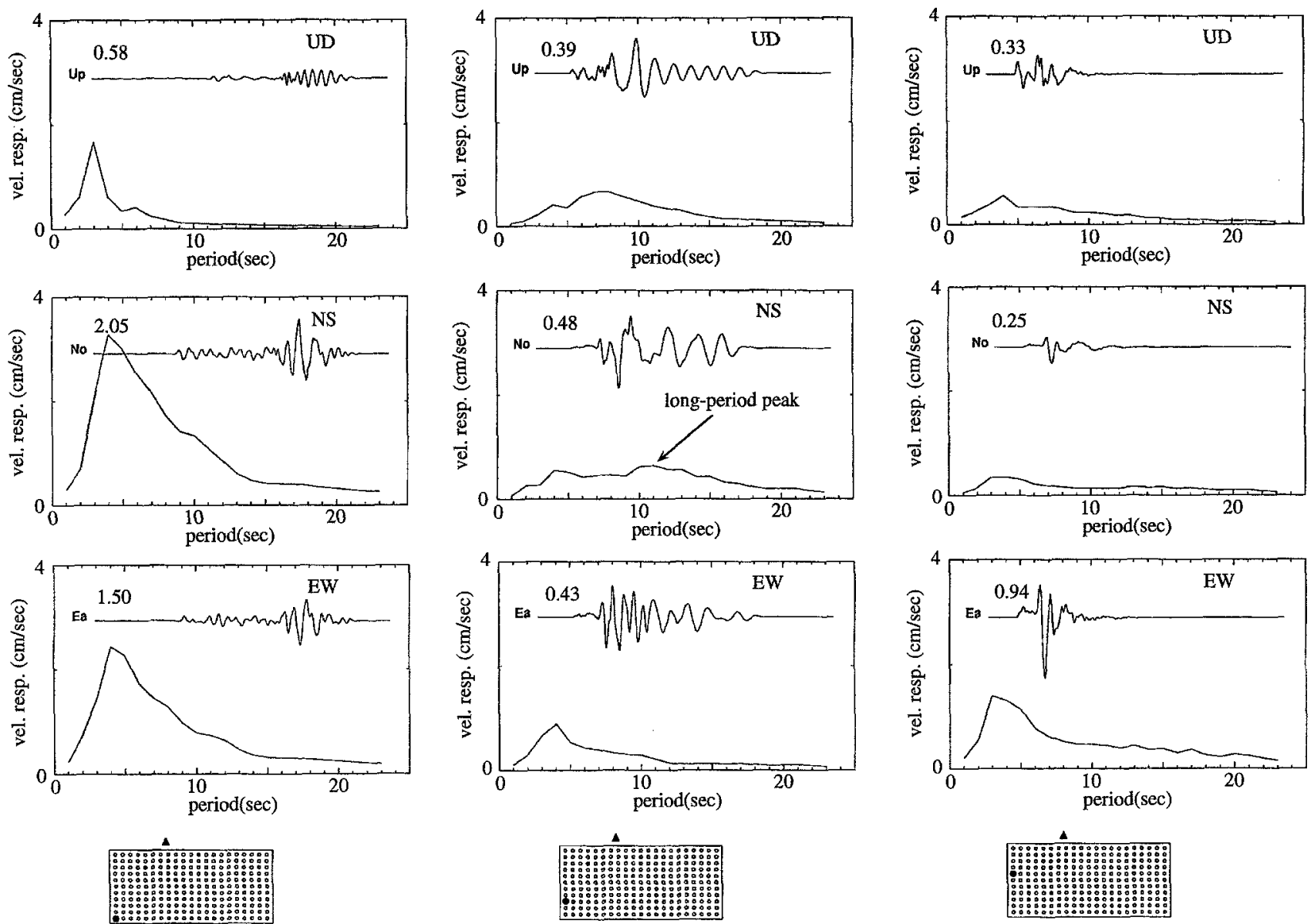

Figure 5. Representative Green's functions used for the Kanto earthquake and their pseudo-velocity response spectra $(h=0.05)$. The horizontal projection of the fault plane is shown at the bottom of each column. The solid circle indicates the hypocenter, and the solid triangle indicates the location of Tokyo. The time constants of the sourcetime function (Fig. 3) are $t_{1}=1.0 \mathrm{sec}$ and $t_{2}=2.0 \mathrm{sec}$. All waveforms are groundmotion velocities in Tokyo calculated using the velocity structure listed in Table 1 . The amplitude of the Green's functions in each column are normalized by a maximum amplitude of the three components, and the peak-to-peak amplitude of each record is listed above each trace.

Representative Green's functions used for the simulations are shown in Figure 5, where velocities of ground motion in Tokyo are indicated along with their velocity response spectra. These Green's functions give ground motions excited by one subfault whose size and slip are $3 \times 3$ $\mathrm{km}^{2}$ and $2.1 \mathrm{~m}$, respectively. Note that when the point source is located in a shallow layer (depth $<10 \mathrm{~km}$ ), short-period surface waves with periods of several seconds are excited. Long-period surface waves (10 to $13 \mathrm{sec}$ ) are excited when the source lies from 5 to $15 \mathrm{~km}$ deep, and spectral amplitudes at short periods are much smaller than that for a shallow source.

\section{Sensitivity of Response Spectra to Fault Parameters}

Rupture Directivity and Slip Distribution. We examined the effects of varying rupture directivity and slip distribution on the velocity response spectra $(h=0.05)$ in Tokyo. We varied the slip distribution on the fault plane as described in the previous section. Rupture directivity was varied using eight rupture propagation models ( $b i, u 1, u 2, c 1, c 2, c 3, c 4$, and $c 5)$ shown in Figure 4. We examined 180 different slip distributions for each model. Figure 6 shows representative results for velocity response spectra using four rupture propagation models $(b i, c 2, c 3$, and $c 5)$. The rupture velocity $\left(v_{r}\right)$ and the time constants $t_{1}$ and $t_{2}$ are set at $3 \mathrm{~km} / \mathrm{sec}, 1 \mathrm{sec}$, and $5 \mathrm{sec}$, respectively. Note that a wide range of velocity response spectra are obtained, even if the fault geometry and seismic moment are fixed. A representative ground velocity for the $c 5$ rupture propagation model that gives the largest response spectrum is shown in Figure 7.

In general, a response spectrum having a sharp peak corresponds to harmonic ground motion, while a smooth spectrum corresponds to an impulsive waveform. Note that the rupture model $c 5$ has markedly different spectra, with a 
(a)
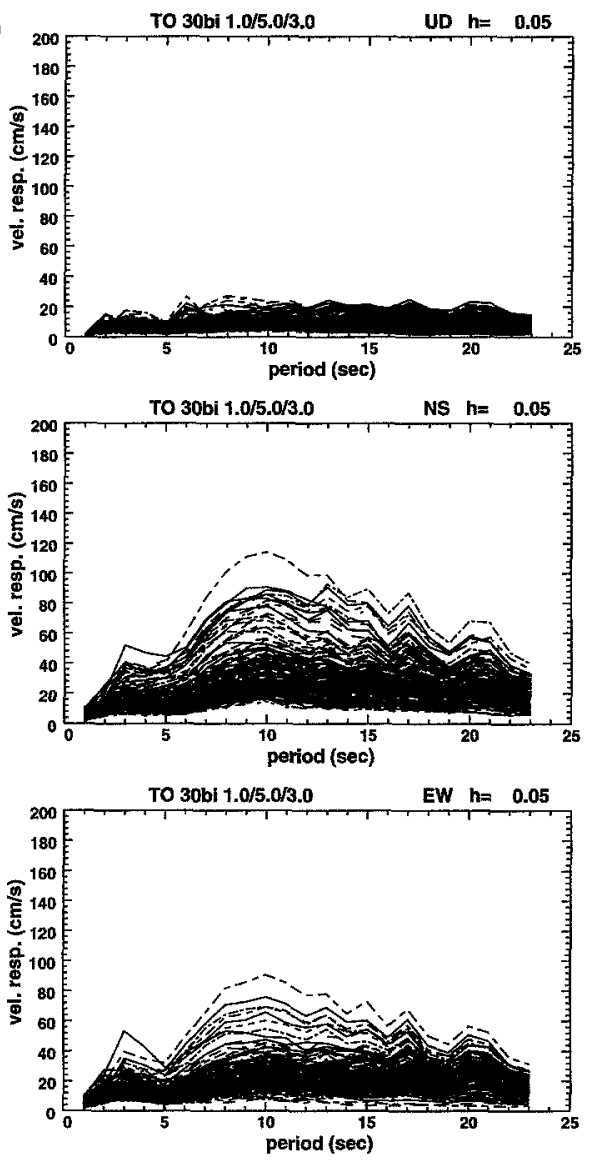

(c)
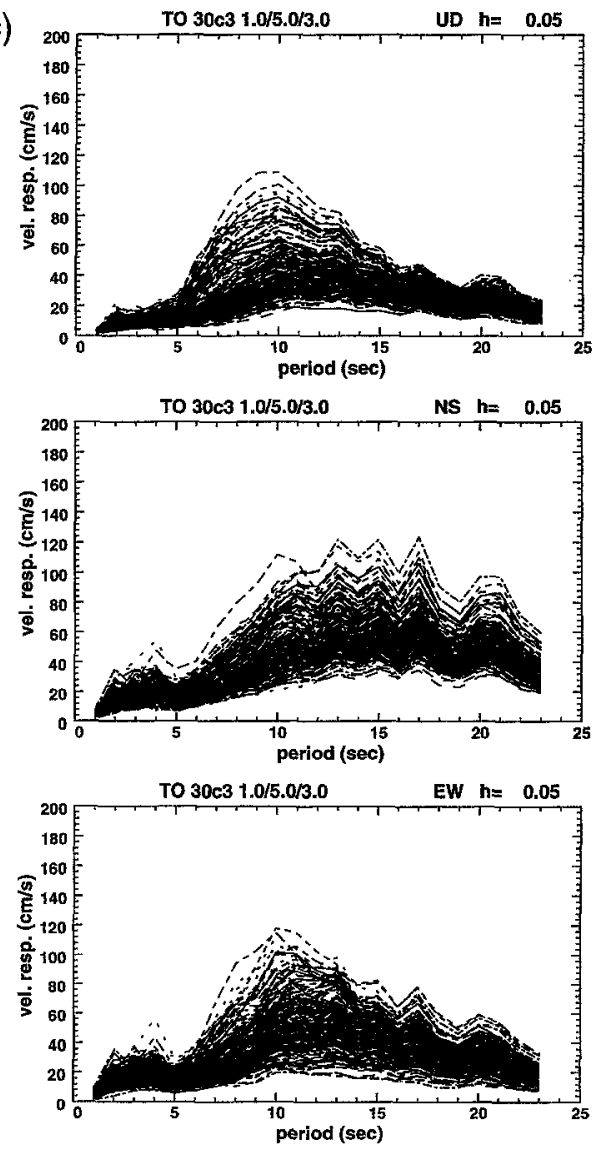

(b)
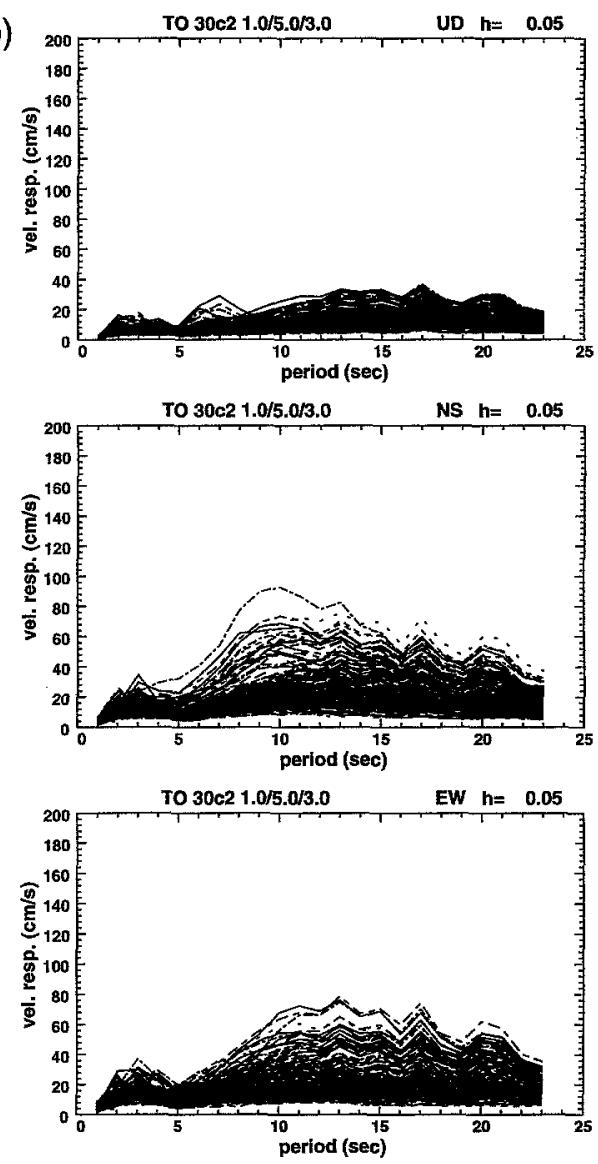

(d)
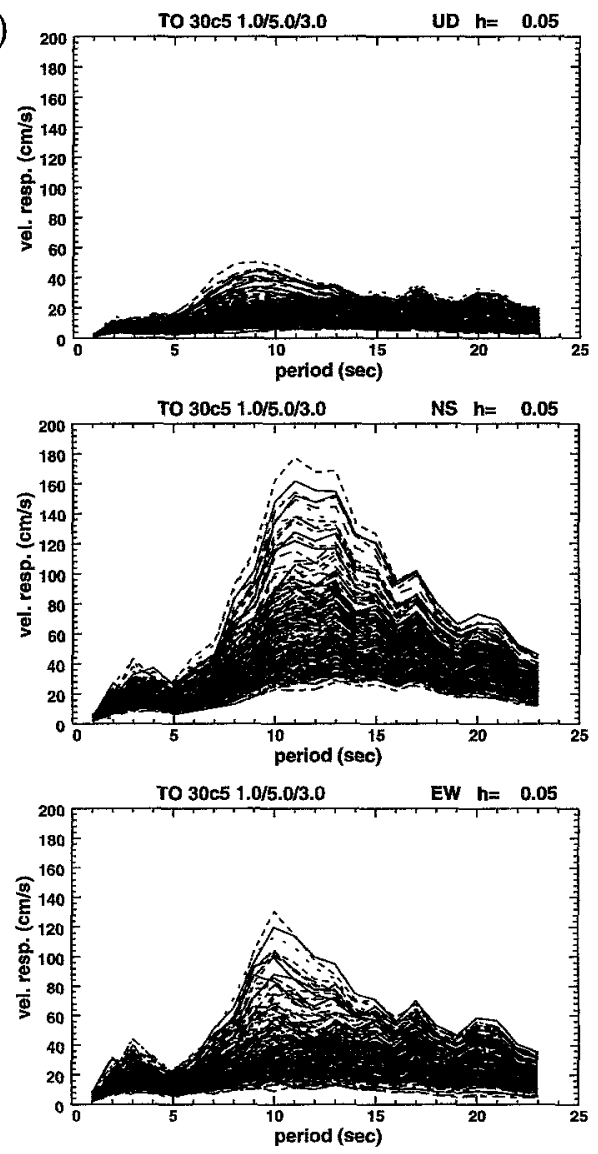
Figure 6. Representative velocity response spectra $(h=0.05)$ for the four rupture propagation models (bi, $c 2, c 3$, and $c 5$ ). The three components are shown. For each rupture model, ground motions are computed for 180 different slip distributions. First two characters in the label shown above each graph indicate the site: e.g., "TO" indicates Tokyo. Next two characters show the spatial resolution parameter $L$ : e.g., " 30 " means $L=30 \mathrm{~km}$. The fifth and sixth characters denote the rupture propagation model, and the next three numbers are the two time constants of the source-time function, $t_{1}$ and $t_{2}$, and the rupture velocity, respectively.
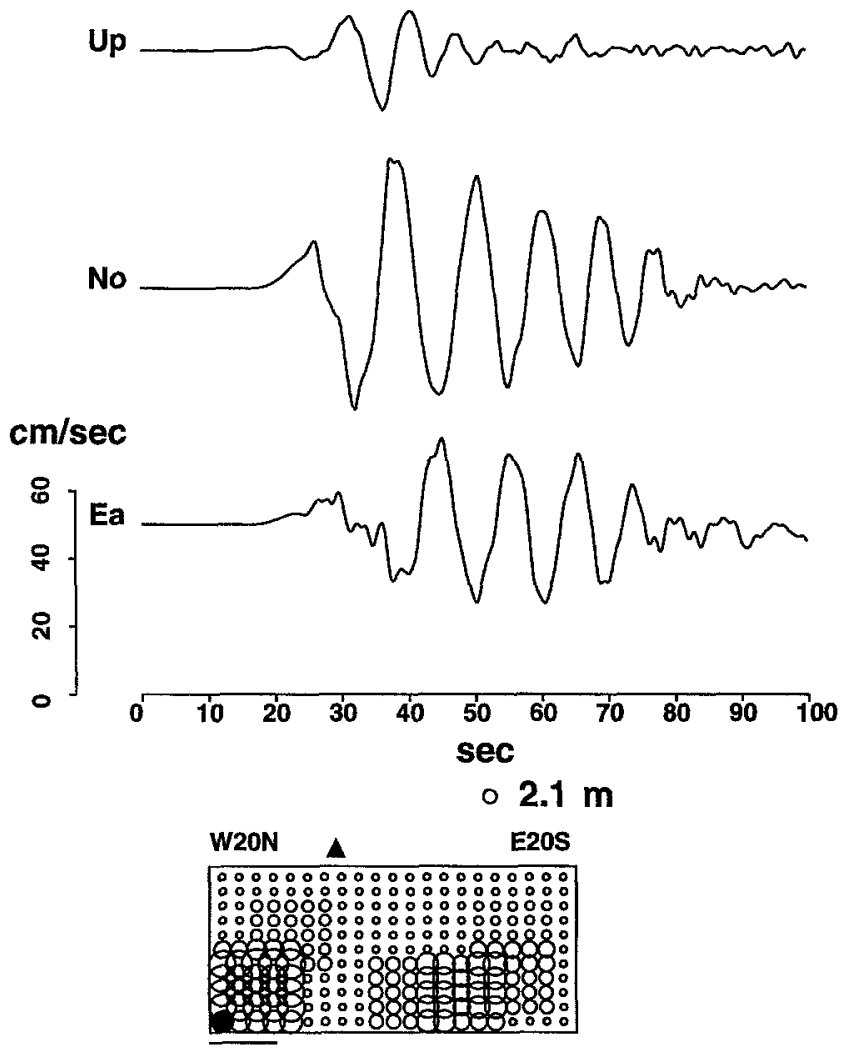

Figure 7. A representative ground velocity for the $c 5$ rupture propagation model. The horizontal projection of the fault plane with slip distribution is shown at the bottom. The area of the circle indicates the amount of slip at every $6 \mathrm{~km}$ on the fault plane. The scale for slip is shown above the fault plane diagram. The solid circle indicates the hypocenter, and the solid triangle indicates the location of Tokyo. The time constants of the source-time function (Fig. 3) are $t_{1}=$ $1.0 \mathrm{sec}$ and $t_{2}=5.0 \mathrm{sec}$. The rupture velocity is set at $3.0 \mathrm{~km} / \mathrm{sec}$.

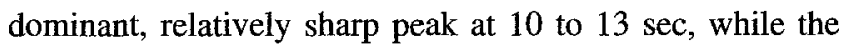
others have broader peaks. Long-period (10 to $13 \mathrm{sec}$ ) surface waves are excited by a source at a depth of about 5 to $15 \mathrm{~km}$, as suggested by the Green's functions shown in Fig- ure 5. However, the amplitude of this long-period wave is relatively small. Thus, we need subfaults having large amounts of slip at a depth of 5 to $15 \mathrm{~km}$ to generate largeamplitude long-period ground motion. To further investigate the excitation mechanism of long-period (10 to $13 \mathrm{sec})$ waves, we performed a test, as shown in Figure 8. Figure 8a shows simulations for rupture propagation models $c 5$ and $c 5^{\prime}$ in which $8.4 \mathrm{~m}$ slip is assumed for a cluster of subfaults at the southwestern corner on a shallow portion of the fault plane. The slip on the other part of the fault plane is assumed to be $1.4 \mathrm{~m}$. The slip distributions are illustrated on the horizontal projection of faults shown in Figure 8a. For each rupture model, we computed ground motions for three slip distributions. The top trace for each component (solid curve) is for the slip distribution shown in the top fault plane on the right of the waveforms. The middle trace (sparsely dotted curve) is for the slip model that consists of the large-slip cluster only. The bottom trace (heavy-dotted curve) is for the slip distribution model without the cluster. Figure $8 \mathrm{a}$ shows that, for $c 5$, the large-slip cluster is almost entirely responsible for the large-amplitude, long-period ground motion. The remaining part of the fault contributes very little to the ground motion. In contrast, for $c 5^{\prime}$, the large-slip cluster excites only small-amplitude ground motion.

The difference between the $c 5$ and $c 5^{\prime}$ models shown in Figure 8a is the location of the hypocenter relative to the large-slip cluster. For $c 5$, rupture propagation on the largeslip cluster is toward Tokyo, but for $c 5^{\prime}$, it is away from Tokyo. These results clearly demonstrate the strong effect of rupture directivity on excitation of ground motion.

Figure $8 \mathrm{~b}$ shows the corresponding velocity response spectra. Figures $8 \mathrm{a}$ and $8 \mathrm{~b}$ clearly demonstrate that if rupture propagates toward Tokyo and a large-slip cluster lies between the epicenter and Tokyo, then the amplitude of the long-period ground motion would increase significantly.

Rupture Velocity. Figure 9a compares simulations for different rupture velocities ranging from $v_{r}=1.5$ to $3.0 \mathrm{~km} /$ $\mathrm{sec}$. The rupture model $c 5$ is used for this simulation. If the rupture velocity is smaller than $2 \mathrm{~km} / \mathrm{sec}$, the ground motion is very small. The corresponding velocity response spectra are shown in Figure $9 \mathrm{~b}$. When $v_{r}$ is increased from 2 to 3 $\mathrm{km} / \mathrm{sec}$, the spectral amplitude at periods shorter than $5 \mathrm{sec}$ increases significantly, but the amplitude changes very little at periods longer than $10 \mathrm{sec}$. In contrast, when $v_{r}$ is decreased from 2 to $1.5 \mathrm{~km} / \mathrm{sec}$, the spectral amplitude at long periods decreases significantly, and the peak at periods longer than $10 \mathrm{sec}$ disappears.

Spatial Resolution Parameter. The simulations thus far have assumed that the spatial resolution parameter $L$ to be $30 \mathrm{~km}$, which is based on the rupture model of the 1968 Tokachi-Oki earthquake. We now examine the effect of varying $L$ on long-period ground motion.

We computed ground motions using the $c 5$ rupture model with $L$ being varied from 12 to $51 \mathrm{~km}$. As Figure 10 
(a)

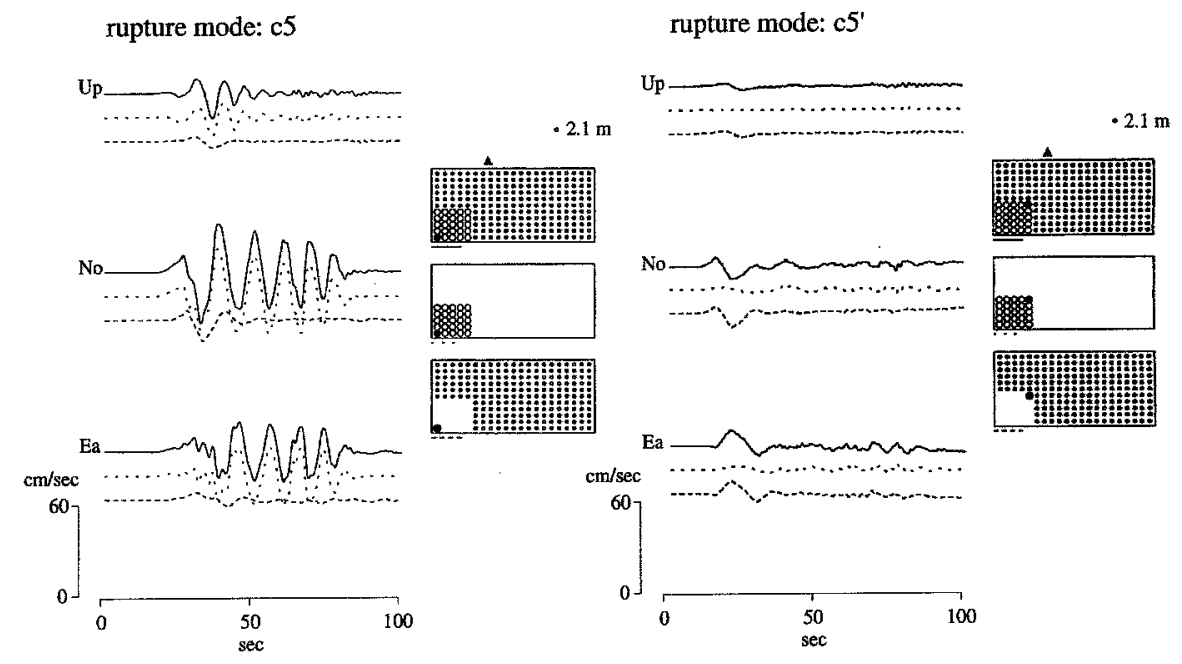

(b)
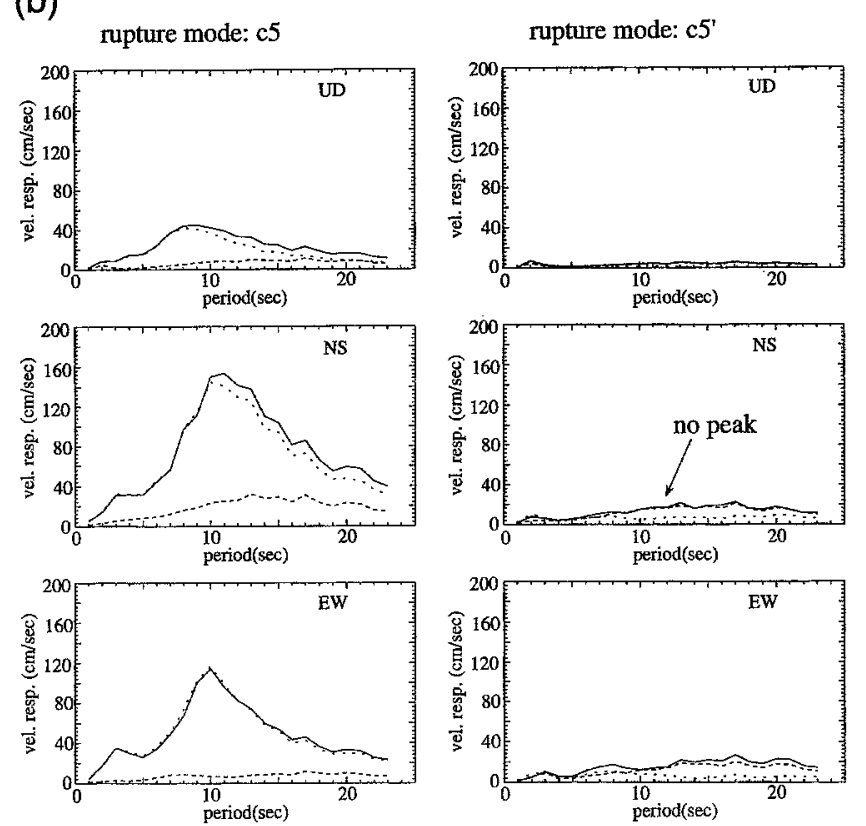

shows, varying $L$ has little effect on ground motion. The dominant period remains between 10 and $13 \mathrm{sec}$, though the amplitude of the spectral peak changes slightly. At $L=51$ $\mathrm{km}$, the rupture time for distance $L$ reaches about $17 \mathrm{sec}$ at $v_{r}=3.0 \mathrm{~km} / \mathrm{sec}$, yet the dominant period at $13 \mathrm{sec}$ is unaffected.

The results of the sensitivity tests shown above clearly demonstrates that directivity and the source depth have a major influence on long-period ground motion. If the rupture velocity is faster than $2 \mathrm{~km} / \mathrm{sec}$, the amplitude of simulated long-period ground motion varies little, and the spatial resolution parameter $L$ has relatively little effect.

\section{Summary of the Kanto Earthquake Simulations}

The response spectra computed using seismologically reasonable sets of source parameters for the 1923 Kanto earthquake vary by more than an order of magnitude. The range of variation of the spectra for Tokyo envelops the
Figure 8. (a) Ground-motion velocities for the two different rupture propagation models. Horizontal projections of the fault plane are shown to the right of the waveforms. The solid circle indicates the hypocenter, and the solid triangle indicates the location of Tokyo relative to the fault plane. The area of the circle indicates the amount of slip at every $6 \mathrm{~km}$ on the fault plane. The scale for slip is shown above the fault plane diagram. The line segment shown at the lower left side of each fault plane diagram indicates the line type used to show the corresponding waveform. (b) Corresponding velocity response spectra $(h=0.05)$. The line type used for response spectrum is the same as that used for the waveforms.

response spectra estimated from the Imamura seismogram and the Ewing seismogram shown in Figure 1c. For some combinations, the response spectra exhibit peaks at about 10 to $13 \mathrm{sec}$ (Fig. 6d), suggesting harmonic ground motion. Thus, even if we cannot prove that the harmonic ground motion estimated from the Ewing seismogram is real, we can conclude that it is not unrealistic. The ground motion estimated from the Imamura seismogram is close to the lower bound of the simulated ground motions. We believe that the reconstruction of the excessively overdriven Imamura seismogram underestimates the real ground motion.

We note that many response spectra shown in Figure 6 have peaks at periods longer than $10 \mathrm{sec}$, longer than the dominant period ( 6 to $8 \mathrm{sec}$ ) estimated from studies of small earthquakes and microtremor measurements (e.g., Tanaka $e t$ al., 1979). Thus, the dominant period of the subsurface structure measured locally may not be representative of the dominant period of ground motion expected for a nearby large 
(a)

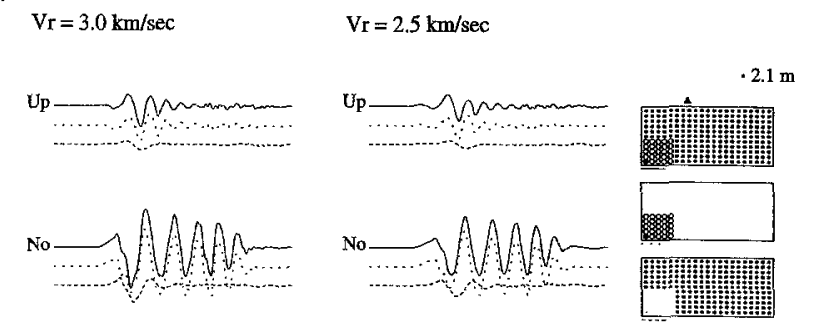

(b)
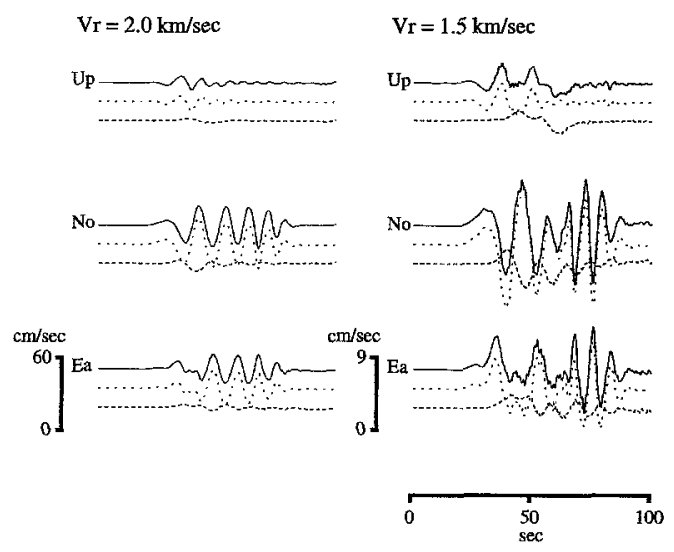

Figure 9. (a) Ground-motion velocities computed for the $c 5$ rupture model (see Fig. 4). Rupture velocities are varied from 1.5 to $3.0 \mathrm{~km} / \mathrm{sec}$. (b) Corresponding velocity response spectra $(h=0.05)$. The line type used for response spectrum is the same as that for the waveform.

earthquake, which is controlled by rupture directivity and source depth.

Because of the relative location of Tokyo with respect to the fault plane, the ground motion in Tokyo is not the largest expected of the 1923 Kanto earthquake. The amplitude in the areas along the southern edge of the fault plane may have been significantly larger than in Tokyo. Sato et al. (1996) reached the same conclusion. The areas in which the collapsed houses reached more than $30 \%$ of the total number in such areas extended along the southern edge of the fault plane, the Shounan area (northern side of the Sagami bay), the Miura peninsula, and the southern part of the Boso peninsula (Imamura, 1925).

Design spectra for high-rise buildings in the waterfront of Tokyo and Yokohama are compared with the velocity response spectra of the $\mathrm{N}-\mathrm{S}$ components using the $c 5$ rupture model (Fig. 11) (Toshiaki Sato, written comm., 1996). Our
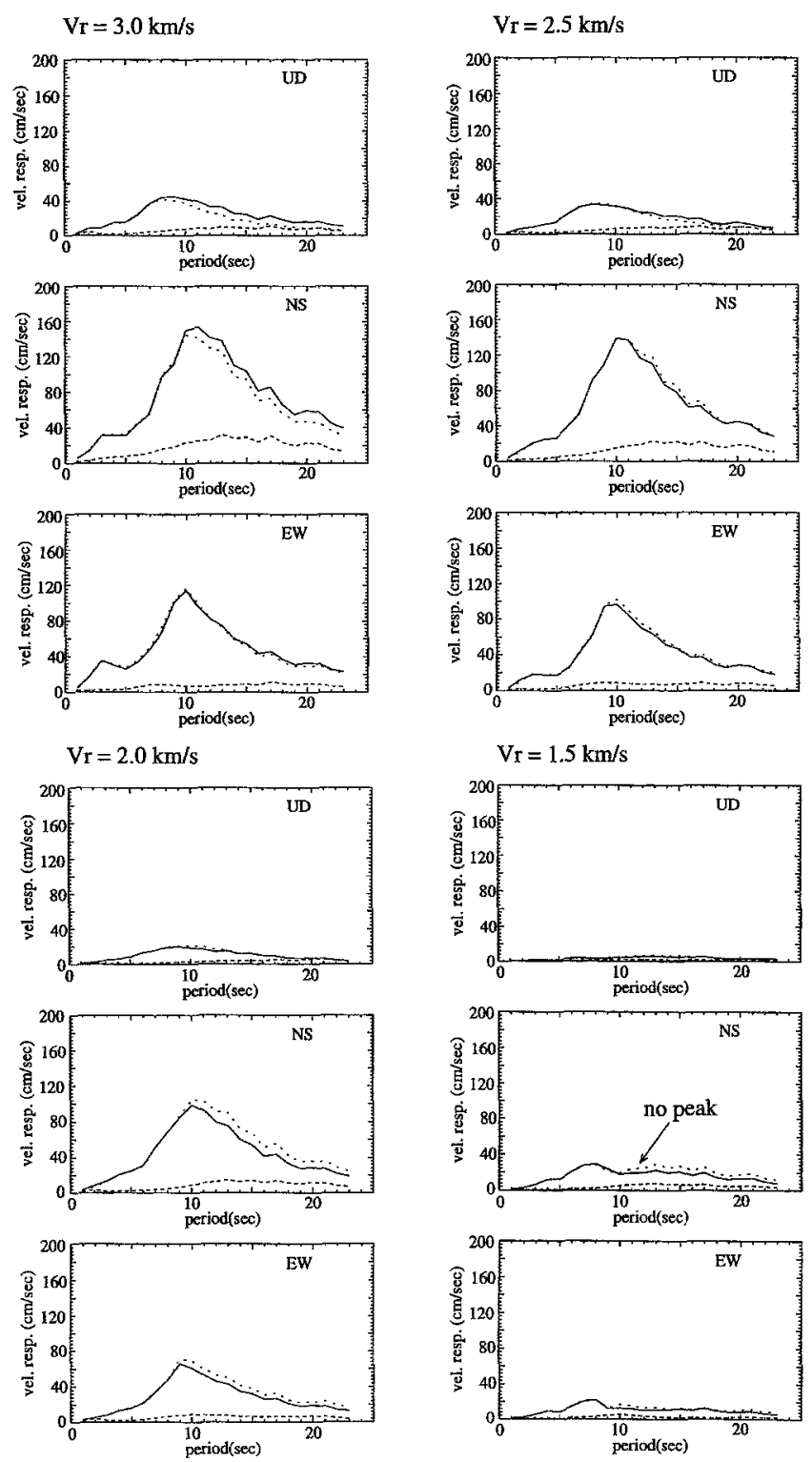

simulation is mainly concerned with long-period waves with periods longer than $5 \mathrm{sec}$. The simulated spectra at periods shorter than $5 \mathrm{sec}$ are small because the smooth source-time function (Fig. 3) was used in the simulation. In the period range longer than $5 \mathrm{sec}$, almost all response spectra exhibit a peak at about 10 to $13 \mathrm{sec}$, ranging from 25 to $170 \mathrm{~cm} /$ sec. In some cases, the spectral amplitudes shown in Figure 11 look exceedingly large compared with the design spectra. We note that the design spectra in Tokyo and Yokohama are about a third of the largest velocity response spectra estimated for a realistic range of fault parameters for an $M=$ 8 earthquake at sites located on a soft sedimentary basin.

\section{Hypothetical Earthquake in the Los Angeles Basin}

Los Angeles is another major urban city located on a thick sedimentary basin where a large earthquake $\left(M_{S}>7.5\right)$ could occur (Heaton et al., 1995; Dolan et al., 1995). 

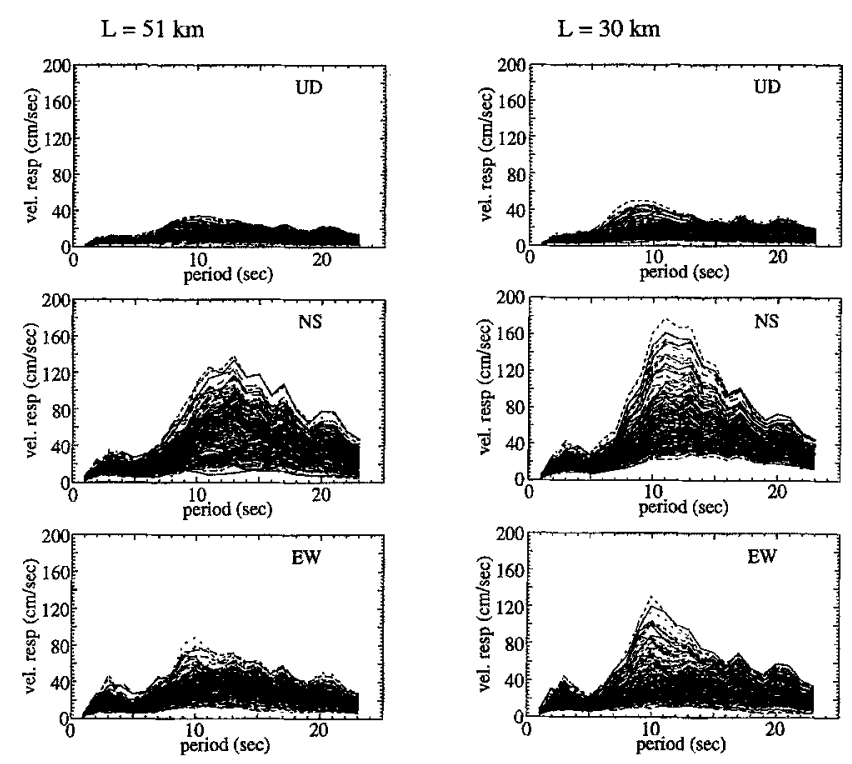

$\mathrm{L}=21 \mathrm{~km}$
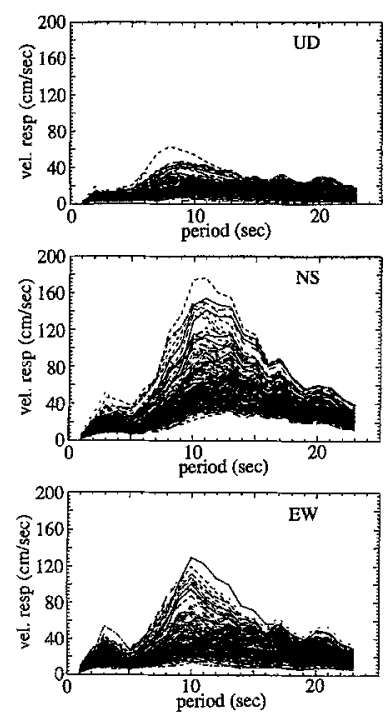
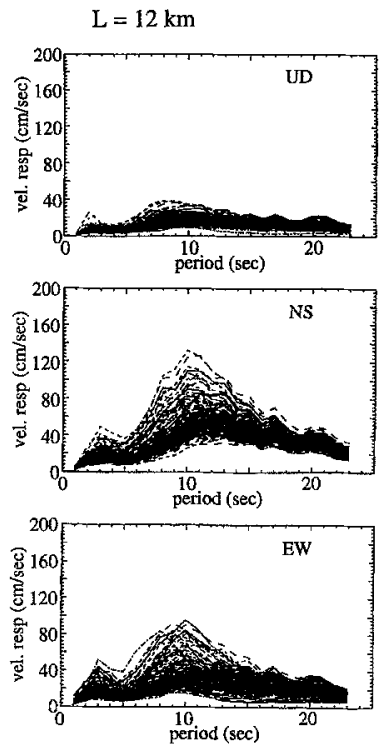

Figure 10. Velocity response spectra $(h=0.05)$ for various $L$ ranging from 12 to $51 \mathrm{~km}$. The rupture model $c 5$ is used. For each $L$, simulations were made for 180 different slip distributions.

In view of the similarity between Tokyo and Los Angeles in this context, and of the results we obtained for Tokyo, we investigated the possible consequence of a large earthquake on ground motion in the Los Angeles basin. Since the method is essentially the same as that used for Tokyo, we just briefly explain the model used for the Los Angeles simulation. Again, our objective here is to explore the possible range of ground motion, rather than to make very specific estimations of ground motion from a scenario earthquake.

We assume an $M_{w}=7.5$ earthquake with a north-dipping reverse fault mechanism similar to that of the 1987 Whittier Narrows earthquake; i.e., dip angle $=30^{\circ}$, and rake

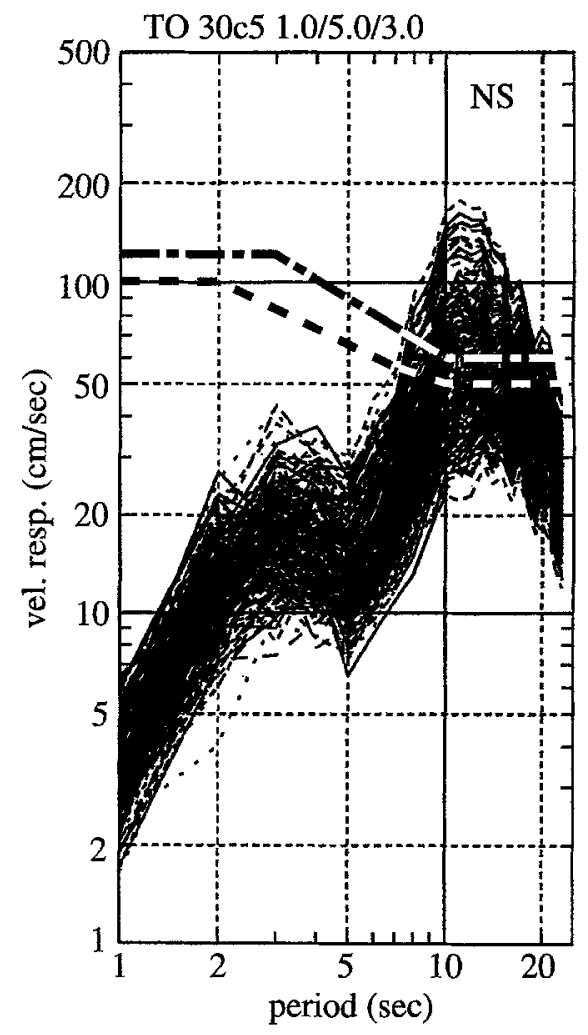

Figure 11. Design spectra for high-rise buildings in the waterfront of Tokyo (short dashed line) and Yokohama (long and short dashed line) with the velocity response spectra ( $h=0.05$ ) of the N-S components for the $c 5$ rupture propagation model.

\section{LA basin fault model}

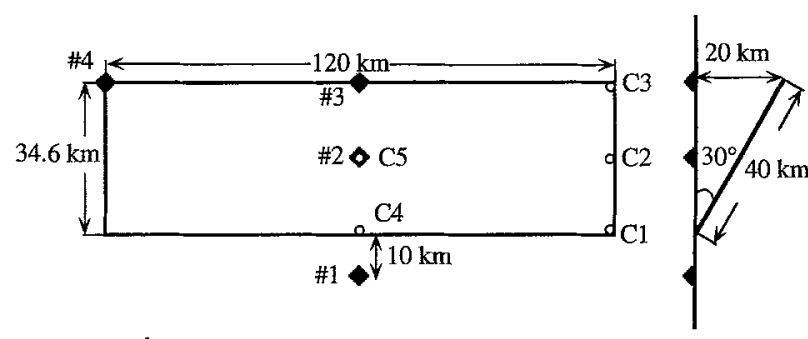

- hypocenter

C1-C6 are six circular rupture modes which initiate from different hypocenters.

- station

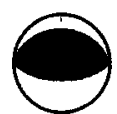

focal mechanism

Figure 12. The horizontal projection and cross section of a fault plane for a hypothetical earthquake beneath the Los Angeles Basin. Rupture propagation models used for the simulations are shown. " $\mathrm{cl}$ " to " $c 5$ " are five circular rupture models. Small, open circles indicate the hypocenters used for the simulations. The focal mechanism used in this article is shown. The locations of sites used for simulations are indicated by solid diamonds attaching the site numbers from 1 to 4 . 
Table 2

Velocity Structure Used for Simulation of the Los Angeles Earthquake

\begin{tabular}{cccccc}
\hline$V_{p}$ & $V_{s}$ & $p$ & $h$ & $Q_{p}$ & $Q_{s}$ \\
\hline 3.00 & 0.95 & 1.80 & 0.00 & 200 & 80 \\
3.00 & 1.35 & 2.05 & 1.00 & 200 & 100 \\
3.00 & 1.90 & 2.20 & 2.30 & 200 & 100 \\
3.81 & 2.30 & 2.40 & 3.50 & 300 & 150 \\
4.33 & 2.60 & 2.50 & 5.50 & 300 & 150 \\
4.85 & 2.90 & 2.60 & 7.00 & 400 & 200 \\
5.20 & 3.10 & 2.70 & 8.50 & 400 & 200 \\
6.41 & 3.70 & 2.72 & 9.60 & 600 & 270 \\
6.76 & 3.90 & 2.75 & 10.80 & 600 & 270 \\
6.76 & 3.90 & 2.75 & 30.00 & 600 & 270 \\
\hline
\end{tabular}

angle $=90^{\circ}$ (Fig. 12). The fault is $120 \mathrm{~km}$ long and $40 \mathrm{~km}$ wide, with an average slip of $2.0 \mathrm{~m}$. For the velocity structure, we used the model determined by Scrivner (written comm., 1992) (Table 2). Velocity response spectra are computed for four sites ( 1 to 4 ) located above the assumed fault plane. Representative Green's functions computed for site 2 are shown in Figure 13 along with their velocity response spectra. These Green's functions are computed for a single $4 \times 4 \mathrm{~km}^{2}$ subfault with $2-\mathrm{m}$ slip, $t_{1}=1.8 \mathrm{sec}$, and $t_{2}=$ $4.0 \mathrm{sec}$ (Fig. 3).

To demonstrate the effect of sedimentary layers on excitation of long-period ground motion, the Green's functions and simulated velocity response spectra for a homogeneous half-space with $P$-wave velocity of $6.41 \mathrm{~km} / \mathrm{sec}$ and $S$-wave velocity of $3.70 \mathrm{~km} / \mathrm{sec}$ are included in Figure 13. These results clearly demonstrate that sedimentary layers play a
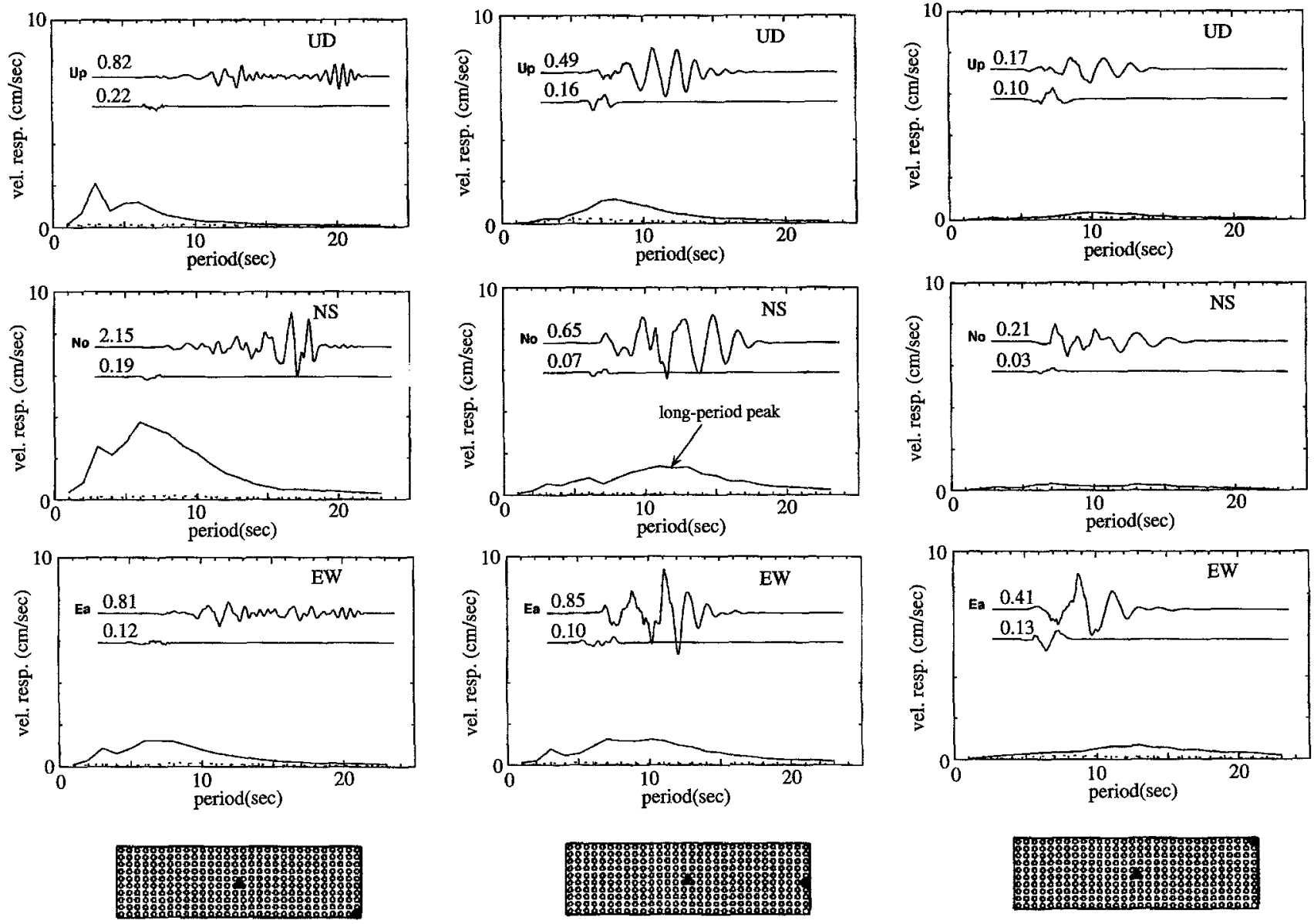

Figure 13. Representative Green's functions used for simulation of the Los Angeles earthquake model and their velocity response spectra $(h=0.05)$. All waveforms are ground-motion velocities at site 2 . The solid circle indicates the hypocenter, and the solid triangle indicates the location of site 2 . The upper traces in each panel are calculated using the velocity structure listed in Table 2 , and their response spectra are shown by solid curves. The lower traces are for a homogeneous half-space with $P$ - and $S$-wave velocities of 6.41 and $3.70 \mathrm{~km} / \mathrm{sec}$, respectively. Their response spectra are shown by dotted curves. The amplitude of Green's functions in each column are normalized by a maximum amplitude of the three components, and the peak-to-peak amplitude of each record is shown above each trace. 
(a)
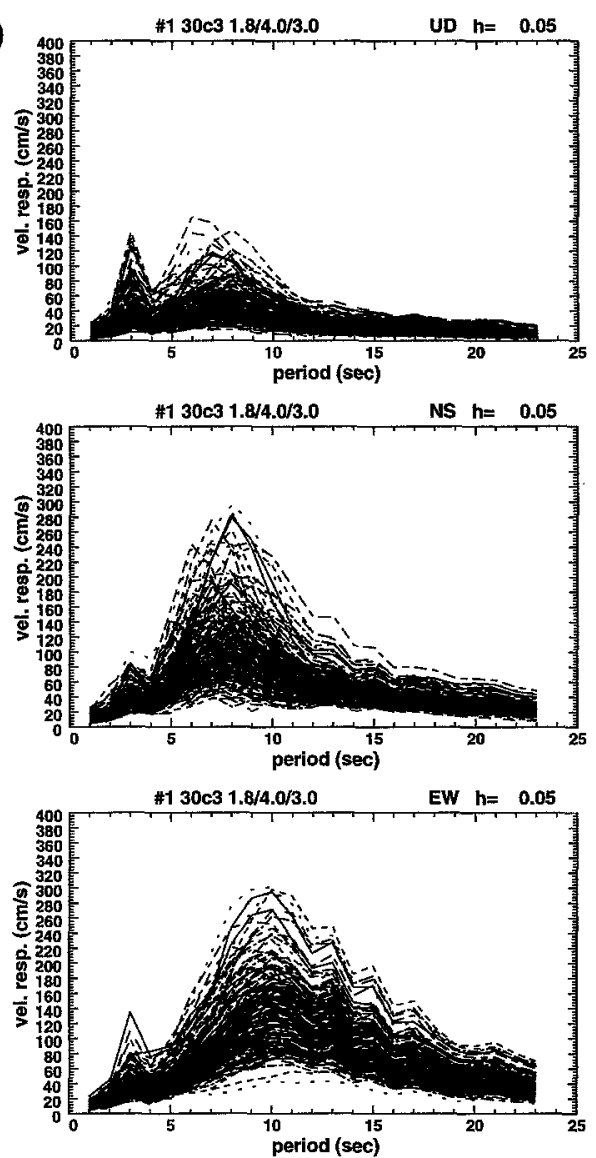

(c)
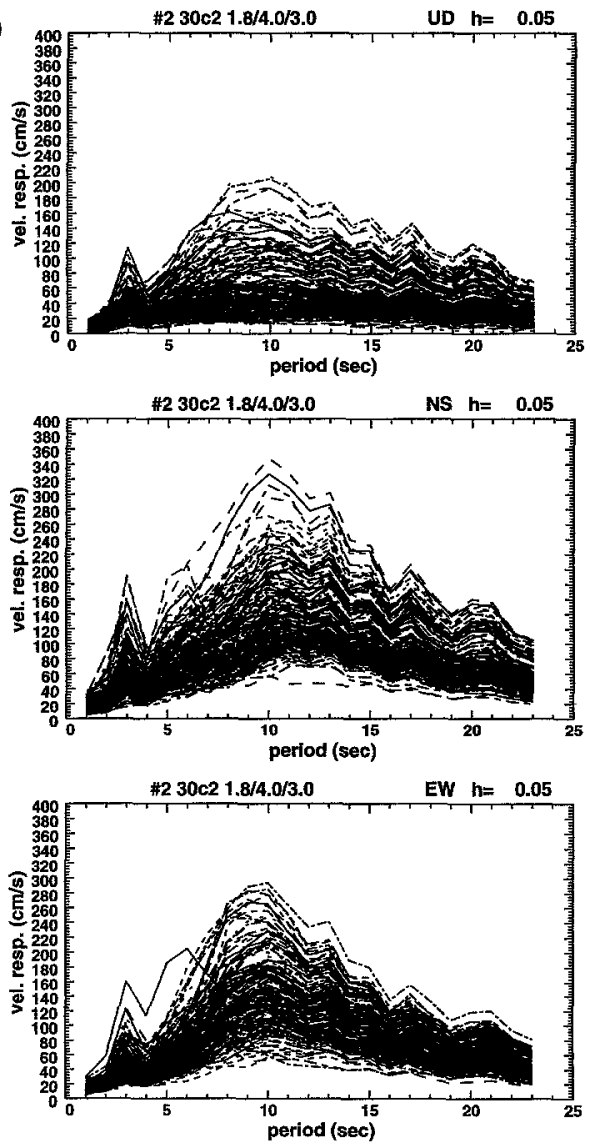

(b)
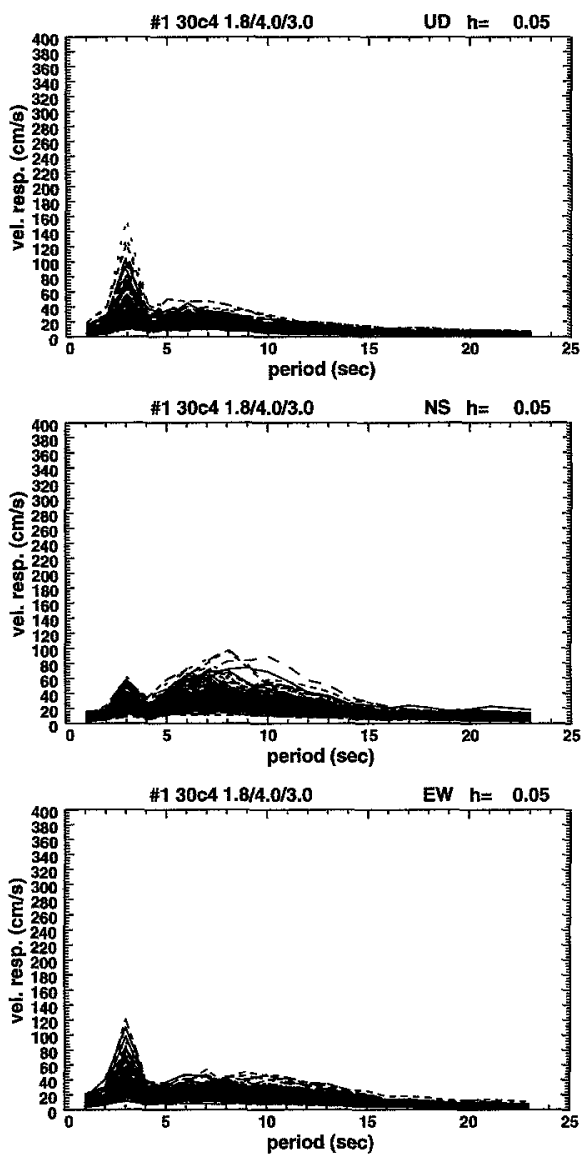

(d)
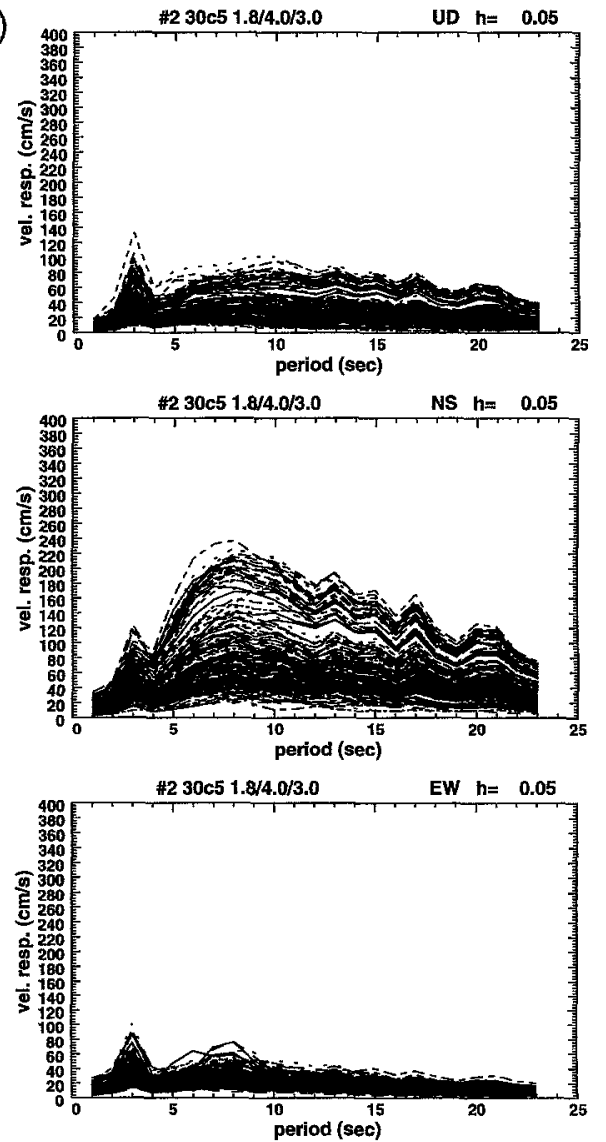
(e)
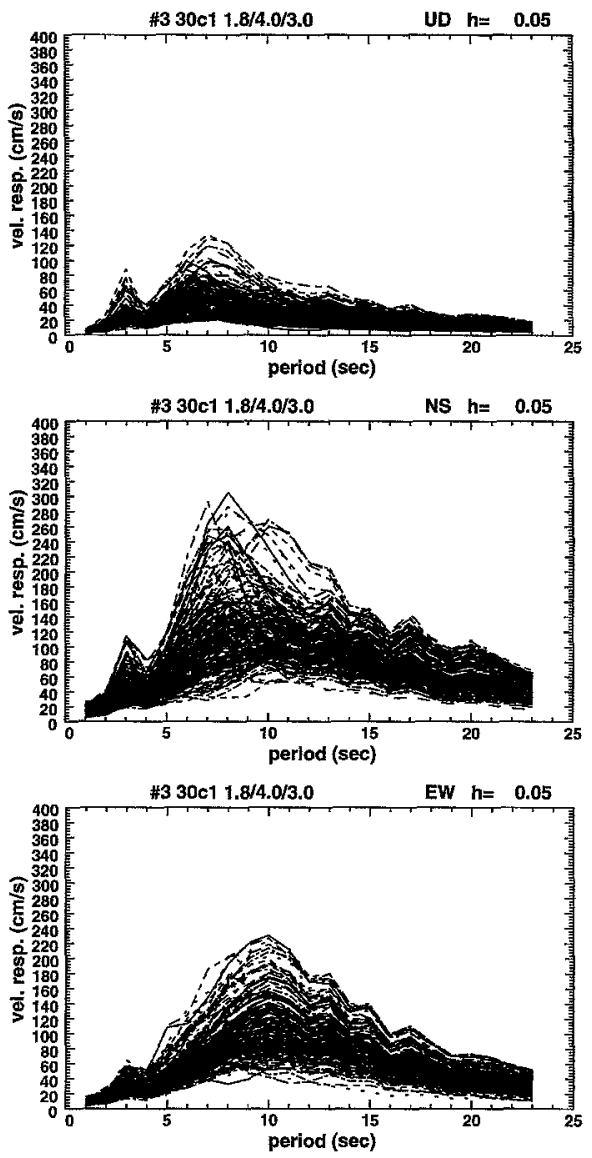

(f)
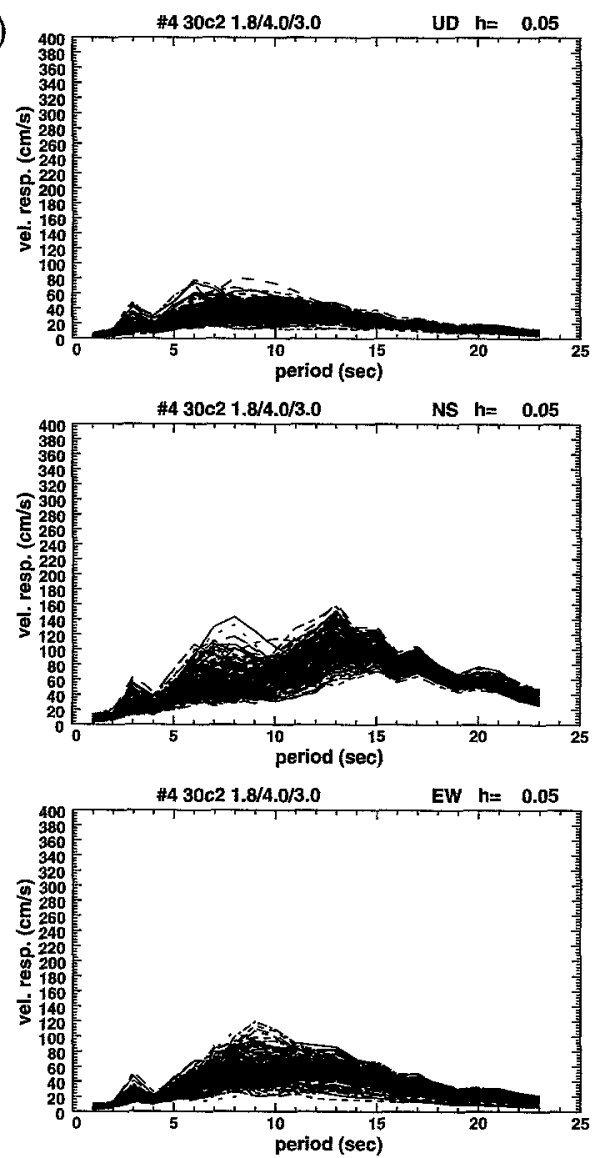

Figure 14. Representative velocity response spectra $(h=0.05)$ for the five rupture propagation models $(c 1, c 2, c 3, c 4$, and $c 5$ ) (see Fig. 12). Three components of ground motion are shown. For each rupture model, ground motions were computed for 180 different slip distributions. The first two characters in the header line of each panel indicate the site number shown in Figure 12.

major role in amplifying long-period ground motion in the epicentral area of a large earthquake. Recently, Olsen et al. (1995) simulated long-period ground motions from a large earthquake $(M=7.75)$ along the San Andreas fault in the Los Angeles area. Their result also shows that the simulated spectral amplitudes for some regions in the Los Angeles basin are up to 10 times larger than those at sites without sedimentary layers.

The response spectra of the Green's functions computed for deeper ( 5 to $15 \mathrm{~km}$ ) sources exhibit a peak at 10 to 13 sec, which is similar to that observed for the Kanto earthquake simulation.

Figure 14 shows representative velocity response spectra for various rupture models $(c 1, c 2, c 3, c 4$, and $c 5)$ and slip distributions with $v_{r}=3.0 \mathrm{~km} / \mathrm{sec}, t_{1}=1.8 \mathrm{sec}$, and $t_{2}$ $=4 \mathrm{sec}$. The spectral amplitude for site 2 computed for the $c 2$ rupture model can reach $350 \mathrm{~cm} / \mathrm{sec}$ at a period of $10 \mathrm{sec}$; Figure 15a shows a representative ground velocity for this case, which gives the largest amplitude. This large amplitude at long period is a result of combined effect of directivity and excitation from sources at a depth of about $10 \mathrm{~km}$. A representative ground velocity for the $c 2$ rupture model at site 4 is also presented in Figure 15b, which gives a longperiod wave train.

Using the same method used for the Kanto earthquake, we investigated the effect of varying $v_{r}$ on velocity response spectra for site 2 , assuming the model $c 2$ rupture model. The result is similar to that obtained for the Kanto earthquake. If $v_{r}<2.0 \mathrm{~km} / \mathrm{sec}$, the amplitude at the dominant period is reduced significantly. Also, as shown in Figure 16, the amplitude of long-period ground motion is relatively insensitive to a variation of $L$ over a range 12 to $32 \mathrm{~km}$.

The spectral amplitudes shown in Figure 14 may look exceedingly large compared with the observed spectrum available to date. However, as we have demonstrated, the source parameters used for computations are all very plausible, so that we must conclude that the range of response spectral amplitude shown in Figure 14 represents a realistic range of ground motion from an $M=7.5$ earthquake at sites located on a soft sedimentary basin. 
(a)

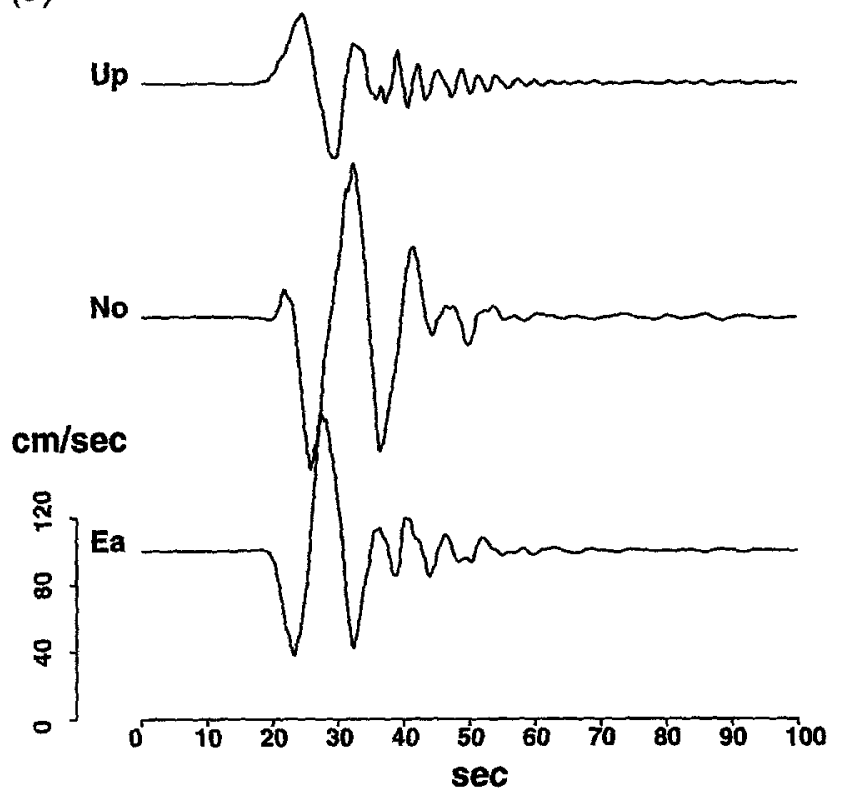

$\circ 2.0 \mathrm{~m}$

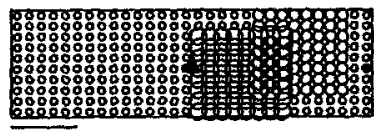

(b)

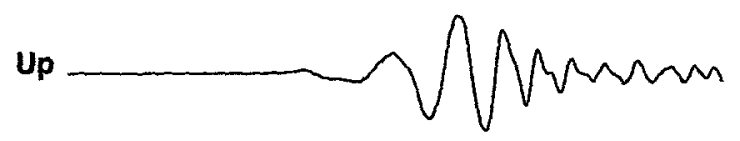

\section{$\mathrm{cm} / \mathrm{sec}$}
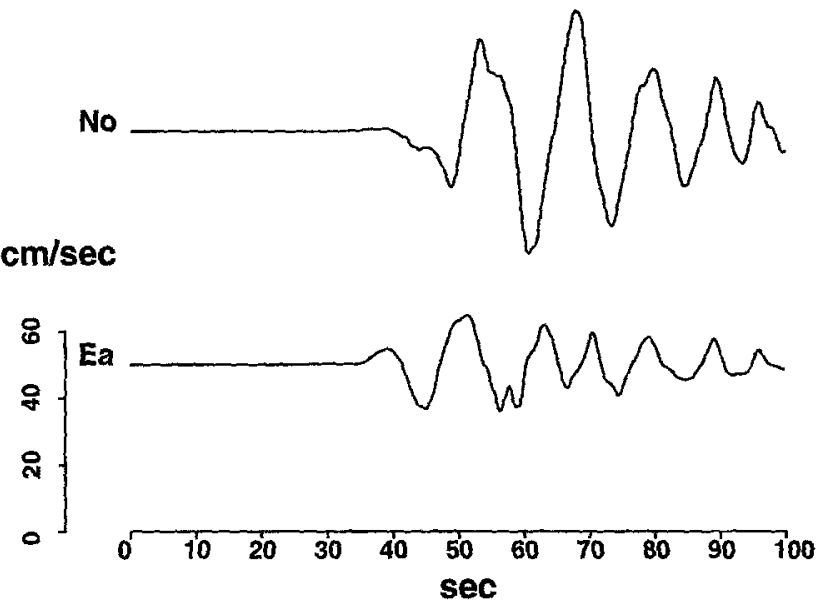

- $2.0 \mathrm{~m}$

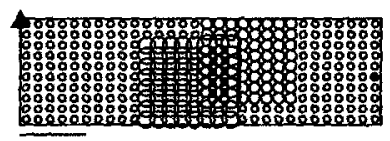

Figure 15. (a) A representative ground velocity for site 2 computed for the $c 2$ rupture model. The horizontal projection of the fault plane with the slip distribution is shown at the bottom. The area of the circle indicates the amount of slip at every $4 \mathrm{~km}$ on the fault plane. The scale for slip is shown above the fault plane diagram. The solid circle indicates the hypocenter, and the solid triangle indicates site 2 . The time constants of the source-time function (Fig. 3) are $t_{1}=1.8 \mathrm{sec}$ and $t_{2}=4.0 \mathrm{sec}$. The rupture velocity is set at $3.0 \mathrm{~km} / \mathrm{sec}$. (b) A representative ground velocity for site $4 \mathrm{com}$ puted for the $c 2$ rupture model. 

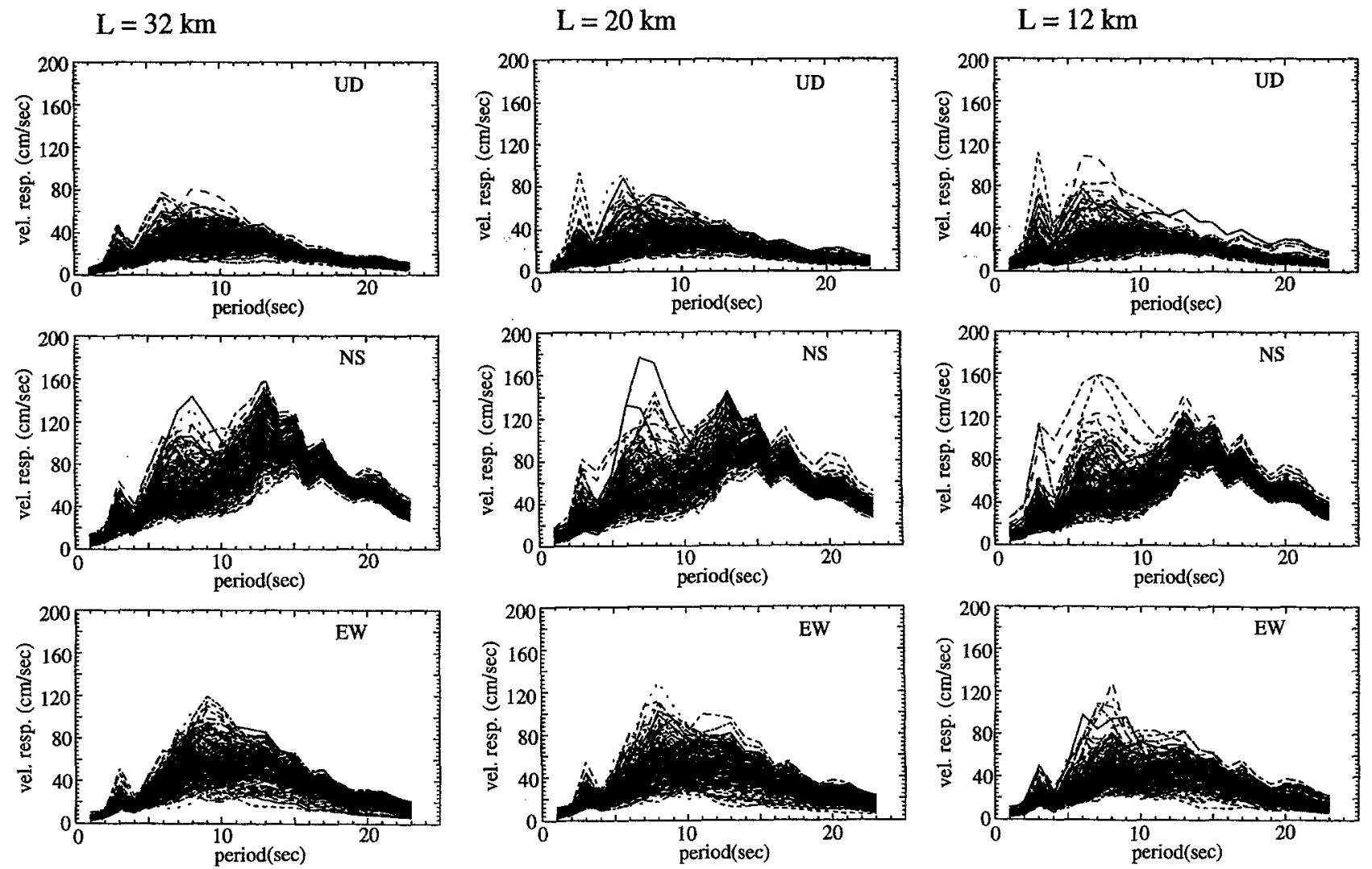

Figure 16. Velocity response spectra $(h=0.05)$ at site 4 for various $L$ ranging from 12 to $32 \mathrm{~km}$. The rupture model $c 2$ is used, and ground motions were computed for 180 different slip distributions for each rupture model.

\section{Conclusions}

We have demonstrated with numerical simulation that rupture directivity and source depth have a profound influence on the amplitude and spectrum of long-period ground motion in the immediate vicinity of large earthquakes. Simulations for the Kanto earthquake show that if the directivity is toward Tokyo, the spectrum of ground motion in Tokyo would have a peak at a period of 10 to $13 \mathrm{sec}$, and the amplitude ranges from 25 to $170 \mathrm{~cm} / \mathrm{sec}$. This large range is expected for fault models with realistic ranges of source parameters. This range is consistent with the observed Imamura and Ewing seismograms. We note that the dominant period of ground motion from a large fault can be significantly different from that estimated from local measurements of microtremors.

The same general conclusion can be made for an $M_{w}=$ 7.5 earthquake model for Los Angeles. For a site just above the center of the fault, the ground-motion spectral amplitude at a period of $10 \mathrm{sec}$ can vary from 50 to $350 \mathrm{~cm} / \mathrm{sec}$. This range, though very large, is what is expected for the seismologically plausible range of source parameters.

\section{Acknowledgments}

We thank H. Yokota and S. Kataoka, Institute of Technology, Shimizu Co., who kindly provided us with the digitized ground-motion data reproduced from the Imamura seismogram, and M. Yamada, Waseda University, who kindly provided us with the digitized ground-motion data reproduced from the Ewing seismogram. This research was partially supported by the CUREe-Kajima Research Project. Contribution No. 5786, Division of Geology and Planetary Sciences, California Institute of Technology, Pasadena, California 91125.

\section{References}

Ando, M. (1971). A fault-origin model of the great Kanto earthquake of 1923 as deduced from geodetic data, Bull. Earthquake Res. Inst. Univ. Tokyo 49, 19-32.

Ando, M. (1974). Seismo-tectonics of the 1923 Kanto earthquake, J. Phys. Earth 22, 263-277.

Bouchon, M. (1981). A simple method to calculate Green's functions for elastic layered media, Bull. Seism. Soc. Am. 71, 959-971.

Dolan, J. F., K. Sieh, T. K. Rockwell, R. S. Yeats, J. Shaw, J. Suppe, G. J. Huftile, and E. M. Gath (1995). Prospects for large or more frequent earthquakes in the Los Angeles metropolitan region, Science 267, 199-205.

Frankel, A. (1993). Three-dimensional simulations of ground motions in 
the San Bernardino Valley, California, for hypothetical earthquakes on the San Andreas Fault, Bull. Seism. Soc. Am. 83, 1042-1063.

Frankel, A. and J. Vidale (1992). A three-dimensional simulation of seismic waves in the Santa Clara Valley, California, from a Loma Prieta aftershock, Bull. Seism. Soc. Am. 82, 2045-2074.

Hamada, N. (1987). Note on the focal depth of the 1923 great Kanto earthquake, Q.J. Seism., Jpn. Meteor. Agency 50, 1-6 (in Japanese).

Heaton, T. H., J. F. Hall, D. J. Wald, and M. W. Halling (1995). Response of high-rise and base-isolated buildings to a hypothetical $\mathrm{Mw} 7.0$ blind thrust earthquake, Science 267, 206-211.

Ide, S., M. Takeo, and Y. Yoshida (1996). Source process of the 1995 Kobe earthquake: determination of spatio-temporal slip distribution by Bayesian modeling, Bull. Seism. Soc. Am. 86, 547-566.

Imamura, A. (1925). Report on the great Kanto earthquake, Rep. Imp. Earthquake Invest. Comm. 100A, 21-65 (in Japanese).

Ishibashi, K. (1985). Possibility of a large earthquake near Odawara, central Japan, preceding the Tokai earthquake, Earthquake Pred. Res. 3, 319 344.

Kanamori, H. (1971). Faulting of the great Kanto earthquake of 1923 as revealed by seismological data, Bull. Earthquake Res. Inst. Univ. Tokyo 49, 13-18.

Kanamori, H. (1974). Long-period ground motion in the epicentral area of major earthquakes, Tectonophysics 21, 341-356.

Kanamori, $H$. and S. Miyamura (1970). Seismological re-evaluation of the great Kanto earthquake of September 1, 1923, Bull. Earthquake Res. Inst. Univ, Tokyo 48, 115-125.

Kennett, L. N. and N. J. Kerry (1979). Seismic waves in a stratified halfspace, Geophys. J. R. Astr. Soc. 57, 557-583.

Kikuchi, M. and Y. Fukao (1987). Inversion of long-period P-waves from great earthquakes along subduction zones, Tectonophysics 144, 231247.

Kudo, K. (1980). A study on the contribution of surface waves to strong ground motions, Proc. 7th World Conf. Earthquake Eng. 499-506.

Kunitomi, S. I. (1930). Seismometrical study of the great Kwanto earthquake occurred on September 1st, 1923, Geophys. Magazine 3, 149164.

Matsu'ura, M., T. Iwasaki, Y. Suzuki, and R. Sato (1980). Statical and dynamical study on faulting mechanism of the 1923 Kanto earthquake, J. Phys. Earth 28, 119-143.

Morioka, T. (1976). Ground motion of the 1923 Kanto earthquake, Proc. 4th Symposium on ground motions, Architectural Inst. Jpn. 38-48 (in Japanese).

Morioka, T. (1980). The ground motion of the great $\mathrm{Kwanto}$ earthquake of 1923, Trans. Architectural Inst. Jpn. 289, 79-88.

Morioka, T. and M. Yamada (1986). An attempt to estimate the maximum ground motion of the great Kanto earthquake of 1923, Proc. 7th Symposium Japanese Earthquake Eng. 109-114.
Olsen, K. B., R. J. Archuleta, and J. R. Matarese (1995). Three-dimensional simulation of a magnitude 7.75 earthquake on the San Andreas fault, Science 270, 1628-1632.

Research Group on Underground Structure in the Tokyo Metropolitan Area (1989). Technical report on the Yumenoshima seismic refraction experiment, $277 \mathrm{pp}$. (in Japanese).

Sato, T., R. W. Graves, P. G. Somerville, and S. Kataoka (1996). Estimates of regional and local strong motions during the great 1923 Kanto, Japan, earthquake (Ms 8.1), Bull. Seism. Soc. Am., submitted.

Takeo, M. (1985). Near-field synthetic seismograms taking into account the effects of anelasticity, Meteor. Geophys. 36, 245-257 (in Japanese).

Takeo, M. and H. Kanamori (1992). Simulation of long-period ground motions for the 1923 Kanto earthquake $(M=8)$, Bull. Earthquake Res. Inst. Univ. Tokyo 67, 389-436.

Tanaka, T., S. Yoshizawa, and Y. Osawa (1979). Characteristics of strong earthquake ground motion in the period range from 1 to 15 secondsanalysis of the low-magnification seismograph records, Bull. Earthquake Res. Inst. Univ. Tokyo 54, 629-655.

Wald, D. J. (1996). Slip history of the 1995 Kobe, Japan, earthquake determined from strong motion, teleseismic, and geodetic data, J. Phys. Earth 44, in press.

Wald, D. J., D. V. Helmberger, and T. H. Heaton (1991). Rupture model of the 1989 Loma Prieta earthquake from the inversion of strongmotion and broadband teleseismic data, Bull. Seism. Soc. Am. 81, $1540-1572$.

Wald, D. J. and P. G. Somerville (1995). Variable-slip rupture model of the great 1923 Kanto, Japan, earthquake: geodetic and body-waveform analysis, Bull. Seism. Soc. Am. 85, 159-177.

Yamanaka, H. (1991). Analysis and modeling of long-period ground motion in the Kanto plain, Japan, Proc. 4th International Conf. Seismic Zonation, 75-82.

Yokota, H., S. Kataoka, and T. Tanaka (1989). Estimation of long-period ground motion of the 1923 great Kanto earthquake, J. Struct. Constr.

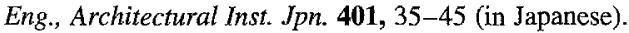

Earthquake Research Institute

University of Tokyo

1-1-1 Yayoi, Bunkyo-ku

Tokyo 113, Japan

(M.T.)

Seismological Laboratory

California Institute of Technology

Pasadena, California 91125

(H.K.)

Manuscript received 17 April 1996. 